\title{
EFFECTS OF NORMAL AGING ON PREFRONTAL AREA 46 IN THE RHESUS MONKEY
}

\author{
Jennifer Luebke ${ }^{1,3}$, Helen Barbas ${ }^{1,2,3}$, and Alan Peters ${ }^{1,3}$ \\ ${ }^{1}$ Department of Anatomy \& Neurobiology, Boston University School of Medicine, Boston, MA \\ ${ }^{2}$ Department of Health Sciences, Boston University, Boston MA \\ ${ }^{3}$ Program in Neuroscience, Boston University, Boston MA
}

\section{Abstract}

This review is concerned with the effects of normal aging on the structure and function of prefrontal area 46 in the rhesus monkey (Macaca mulatta). Area 46 has complex connections with somatosensory, visual, visuomotor, motor and limbic systems and a key role in cognition, which frequently declines with age. An important question is what alterations might account for this decline. We are nowhere near having a complete answer, but as will be shown in this review, it is now evident that there is no single underlying cause. There is no significant loss of cortical neurons and although there are a few senile plaques in rhesus monkey cortex, their frequency does not correlate with cognitive decline. However, as discussed in this review, the following do correlate with cognitive decline. Loss of white matter, that has been proposed to result in some disconnections between parts of the central nervous system, and changes in the structure of myelin sheaths, that reduce conduction velocity and the timing in neuronal circuits. In addition, there are reductions in the inputs to cortical neurons, as shown by regression of dendritic trees, loss of dendritic spines and synapses, and alterations in transmitters and receptors. These factors contribute to alterations in the intrinsic and network physiological properties of cortical neurons. As more details emerge it is to be hoped that effective interventions to retard cognitive decline can be proposed.

\section{Keywords}

Frontal cortex; primate; cognition; working memory; Macaque

\section{Overview}

This review is concerned with the effects of normal aging on the structure and function of prefrontal area 46 in the rhesus monkey. Even though more work needs to be done, in terms of normal aging area 46 is probably the most completely studied of the neocortical areas involved in the mediation of cognitive abilities such as working memory. Rhesus monkeys are an ideal primate model for studying normal aging for several reasons: they have a maximum lifespan of 35 years (Tigges et al., 1988) but are not subject to Alzheimer's disease, their brains

(C) 2009 Elsevier B.V. All rights reserved.

Corresponding author: Jennifer Luebke, PhD. M949, 85 E. Newton St., Boston, MA 02118. jluebke@ bu.edu; phone: 617-638-4930; fax: 617-638-5954.

Publisher's Disclaimer: This is a PDF file of an unedited manuscript that has been accepted for publication. As a service to our customers we are providing this early version of the manuscript. The manuscript will undergo copyediting, typesetting, and review of the resulting proof before it is published in its final citable form. Please note that during the production process errors may be discovered which could affect the content, and all legal disclaimers that apply to the journal pertain. 
do not acquire neurofibrillary tangles and they have few senile plaques in the cortex. Since humans can live for about one hundred years, and the life-span of monkeys is about 35 years, as a rule of thumb it can be assumed that one monkey year is approximately equal to three human years. This also fits with the fact that monkeys are sexually mature at 5 years of age, and humans at about 13-15 years of age. Another advantage of studying monkey is that over their entire life-span monkeys can be behaviorally tested to determine their cognitive status, and then their brains prepared for anatomical and other assessments. Consequently it can be determined if age-related decline in cognitive status can be correlated with any of the morphological, physiological, or biochemical alterations that occur with age. For example, the few senile plaques present have a predilection for the frontal and primary somatosensory cortices in monkeys (Struble et al., 1985; Heilbroner and Kemper, 1990; Sloane et al., 1997), and their numbers increase with age, as they do in humans. However, although both plaque burden and cognitive decline tend to increase with age, there is no correlation between plaque density and the extent of age-related behavioral dysfunction (Sloane et al., 1997). Incidentally, in healthy humans as in monkeys, the predominant form of amyloid is $\mathrm{A} \beta_{40}$, but in Alzheimer's disease, which monkeys do not get, the prevalence of $A \beta_{42}$ is increased (Gearing et al., 1996; Kanemaru et al., 1996). This likely means that the processing of amyloid is different in humans and monkeys, but at present the significance of this fact is not evident, although it may relate to the low plaque frequency in monkeys.

Prefrontal area 46, specifically its central and caudal parts, has been associated with working memory since the classic work of Jacobsen (Jacobsen, 1936). This cortical area has a critical role in a range of cognitive tasks that require keeping in mind information on a temporary basis to accomplish a task at hand, or to keep track of self-generated responses to complete tasks with several components, such as following road directions, or a recipe [for reviews see (Goldman-Rakic, 1988; Fuster, 1989; Fuster, 1993; Funahashi and Takeda, 2002)]. In nonhuman primates the role of area 46 in working memory has been shown through delayed response tasks using a variety of sensory stimuli and requiring a variety of responses involving hand movement to retrieve a reward, oculomotor responses, or delayed alternation responses [e.g., (Carlson et al., 1997)]. Damage to area 46 in non-human primates creates a blind spot specific for temporary memory, and impairs the ability to accomplish the task at hand (Jacobsen, 1936; Funahashi et al., 1993), leaving other types of memory intact. The simplicity of the tasks that are disrupted belies the complexity of information necessary to accomplish them. As will be shown in a later section, area 46 communicates with a host of cortical and subcortical structures that makes it possible to use information flexibly for cognitive operations.

\section{Age-related changes in area 46-mediated cognitive abilities in the rhesus monkey}

As described above, area 46 plays a critical role in the mediation of executive functions, including working memory. These executive functions, essential for accomplishing tasks of daily living, are among the earliest cognitive abilities to decline during normal aging in both humans (Albert, 1993; Salthouse et al., 2003; Fisk and Sharp, 2004; Rhodes, 2004; RodriguezAranda and Sundet, 2006; Sorel and Pennequin, 2008) and non-human primates (Bartus et al., 1979; Rapp, 1990; Lai et al., 1995a; Steere and Arnsten, 1997; Herndon et al., 1997; Voytko, 1999; Moore et al., 2003; Moore et al., 2005; Moore et al., 2006).

In the rhesus monkey, executive function has been assessed primarily with visual reversal learning tasks (both spatial and object modalities). In order to succeed at these tasks, monkeys must be able to shift from an initial learned stimulus-reinforcement pair to a different stimulusreinforcement pair. Performance on reversal learning tasks provides a measure of set-shifting ability, which is an indication of cognitive flexibility. Impairment on reversal learning tasks is 
manifested both as an inability to shift set and as an increase in perseveration. Bartus and colleagues were the first to demonstrate significant impairment of reversal learning in aged rhesus monkeys (Bartus et al., 1979). Several years later there was a report that initial learning of the reversal learning task required more training in aged compared to young monkeys, while overall reversal learning was largely intact, leading to the idea that attentional deficits during task acquisition contribute significantly to cognitive deficits in aged monkeys (Rapp, 1990). By contrast, another study reported that there is no difference between aged and young subjects in initial learning of spatial and object reversal tasks, but found that aged monkeys as a group are significantly impaired on spatial but not object reversals (Lai et al., 1995a). Importantly, these investigators also noted a distinct perseverative tendency of aged monkeys on both spatial and object reversals (Lai et al., 1995a).

In one comprehensive study of cognitive decline in aging rhesus monkeys, the performance of early (19-23 years old), advanced (24-28 years old), and oldest ( $\geq 29$ years old) aged monkeys were compared to that of young adults $(<15$ years old) on a variety of tasks that test cognitive and mnemonic function, including: (1) acquisition of the delayed non-matching-to-sample task (DNMS); (2) performance of the DNMS with a delay of $120 \mathrm{sec}$; (3) the spatial condition of the delayed recognition span test (DRST); (4) the color condition of the DRST; (5) spatial reversal learning; (6) object reversal learning; and (7) a composite Cognitive Impairment Index (CII) score which was derived from the average of the three standardized scores DNMS basic task, the DNMS 2-minute delay and DRST spatial condition using the guidance of a principal components analysis (Herndon et al., 1997). Both early-aged and oldest-aged monkeys were significantly impaired on all tasks except on the DRST-color, and the highest degree of impairment was seen in spatial memory (DRST). Progressively higher impairment rates were seen with increasing age for DNMS-acquisition, DRST-color and spatial reversal learning tasks and the CII. Recently, a new task termed the Conceptual Set Shifting Task, has been developed and employed to assess abstraction, concept formation and set shifting in monkeys in a similar way to the Wisconsin Card Sorting Test used in human studies (Moore et al., 2005). Aged monkeys ( $>20$ years old) are significantly impaired in the acquisition and performance on the Conceptual Set Shifting Task and also exhibit a high degree of perseverative responding relative to young adult monkeys (5-10 years of age; (Moore et al., 2005).

There is thus now a relatively large body of literature demonstrating that aged monkeys are impaired in executive function relative to young monkeys. With this established, it is important to determine the age at which this dysfunction begins. A recent study determined that middleaged monkeys (10 to 20 years old) are significantly impaired on the Conceptual Set Shifting Task as are the aged subjects (Moore et al., 2006). These findings are consistent with those of human studies which have shown a significant increase in perseverative errors on the Wisconsin Card Sorting Test by middle-age (Rhodes, 2004).

Taken together, these behavioral studies support the idea that in the rhesus monkey executive function (mediated in part by area 46) undergoes significant decline fairly early during the aging process. However, in terms of cognitive impairment within any aged population of monkeys, there is a clear gradient of cognitive performance, with many aged monkeys being impaired while others are unimpaired and indistinguishable from young monkeys. Hence, as with the human population, some aged monkeys are "unsuccessful agers" and some are cognitively spared and are "successful agers".

\section{Architecture of area 46}

Area 46 is situated in the center of the lateral surface of the forebrain in macaque monkeys and humans. In macaque monkeys it occupies the banks of the principal sulcus nearly throughout the entire extent of the sulcus, except at its rostral and caudal tips, which are occupied by area 
10 in the frontal pole, and area 8 in front of the concavity of the arcuate sulcus (Fig. 1). Beyond the principal sulcus, area 46 extends to the gyral surface above, where it shares a border with area 9 , and below the sulcus it abuts area 12 .

In Nissl stained sections, area 46 has the appearance of a typical granular cortex, since layer 4 contains small and closely packed neurons (Fig. 1 B, C). However, layer 4 is of variable thickness, so that its upper border with layer 3 is not always well defined. The neurons in layer 3 are larger than those in layer 4 , and there is a scattering of quite large, darkly staining pyramidal neurons in the lower portion of layer 3 . Towards the upper part of layer 3 the neurons gradually become smaller. Layer 2 is composed of small neurons and has a well-delineated border with layer 1 , which contains few neurons. The border between layer 4 and layer 5 is also irregular, but it is conspicuous because layer 5 contains large and medium sized pyramidal neurons that are more loosely packed than the small neurons of layer 4 . Defining the exact border between layer 5 and layer $6 \mathrm{~A}$ can be difficult, although the neurons of layer $6 \mathrm{~A}$ tend to be more rounded than the pyramidal shaped neurons of layer 5 . In contrast, the border between layer 6A and 6B is easily discerned because the neurons in layer 6B are mainly horizontal neurons, and they intermix with the myelinated fibers of the upper strata of the white matter (O'Donnell et al., 1999).

Area 46 can be subdivided into anterior and posterior sectors, and each sector is further subdivided into a dorsal and a ventral part (Fig. 1A). There is general agreement on the overall extent of area 46 in rhesus monkeys, though not for the number or borders of its more subtle subdivisions. On the basis of the neuronal architecture, the various maps generally agree that the cortex buried in the principal sulcus is part of area 46 (Walker, 1940;Barbas and Pandya, 1989;Preuss and Goldman-Rakic, 1991;Petrides and Pandya, 1999), as is its small extension above and below the principal sulcus. In a recent study the caudal extension of area 46 into the adjacent gyri has been renamed 9/46d (above the principal sulcus) and 9/46v (below the principal sulcus) in an attempt to make it consistent with terminology used for the human (Petrides and Pandya, 1999). The architectonic boundaries of the various subdivisions are subtle, and the most prominent architectonic difference, detected using quantitative architectonic methods, is a higher density of the calcium binding protein calbindin in rostral compared to caudal area 46 (Dombrowski et al., 2001).

According to the analysis carried out by Petrides and Pandya (1999), by comparison to the monkey, in the human brain area 46 occupies the middle portion of the middle frontal gyrus, with a considerable portion of the area buried in the depths of the middle frontal sulcus. Petrides and Pandya (1999) state that only a constricted portion of what had been previously labeled as area 46 in the monkey brain has the same cytological characteristics as area 46 in the human brain, and for a full discussion of the complexities involved in considering the homologies between the human and monkey prefrontal cortices it is recommended that the article by Petrides and Pandya (1999) be consulted.

\section{Effects of age on volume, neuronal numbers, and minicolumns}

On the basis of early studies of the effects of age on cerebral cortex it was assumed that any loss of cognition with age is due to a substantial loss of neurons from the cerebral cortex. However, as more rigorous studies have been carried out, it has become evident there is no significant age-related loss of cortical neurons during normal aging and that the erroneous conclusions of earlier investigators were due to problems in counting techniques (Peters et al., 1998a). The question of whether there is loss of neurons from area 46 of monkey prefrontal cortex has been thoroughly examined in the past few years. The issue was first addressed by Peters et al. (Peters et al., 1994), who found no change in the numbers of neuronal profiles in strips of sections extending through the depth of area 46, and no indication that neurons are 
dying. More recently, Smith et al. (Smith et al., 2004) have also examined the effects of age on neuronal numbers in both areas 46 and $8 \mathrm{~A}$ of behaviorally tested monkeys and on the basis of a stereological analysis they agree that there is no decline in the total numbers of neurons in area 46 with age. Surprisingly, however, they did find a $32 \%$ loss of neurons from adjacent area $8 \mathrm{~A}$ with age, leading them to conclude that any age-related loss of neurons from the cortex is focal.

Other studies have applied stereological methods to estimate the volume of area 46 in Nissl stained sections, and found no change with age, indicating that a loss of grey matter from this cortical area is not the basis of age-related behavioral deficits (O'Donnell et al., 1999). A recent magnetic resonance imaging (MRI) study on the effects of age on gray matter of rhesus monkey cortex however reports a small loss of gray matter from several cortical areas, including the dorsolateral prefrontal cortex, where area 46 is located, and concludes that the loss of gray matter is associated with the decline in working memory exhibited by the monkeys (Alexander et al., 2008). This loss of gray matter amounts to about a $13 \%$ thinning of the cortex (Alexander et al., 2008), but in earlier studies in which the thickness of the cortex of area 46 was measured in Nissl stained sections, no change in thickness was found with age, and so the true state of affairs is unclear (Peters et al., 1994; (O'Donnell et al., 1999). However, it can probably be concluded that any decrease in the thickness of the cortex with age is minimal, except perhaps for layer 1 . In area 46 the width of layer 1 decreases by about $25 \%$ (as assessed using $1 \mu \mathrm{m}$ sections), although there is no loss of neurons from layer 1 with age (Peters and Sethares, 2002b). The thinning is accompanied by a loss of dendrites and dendritic spines from the apical tufts of pyramidal neurons (Peters et al., 1998b), and interestingly, the thinning correlates with a deficit in the performance of monkeys in a delayed non-matching to sample task. However, contrary to these observations, O'Donnell et al. (O'Donnell et al., 1999) subsequently measured the thickness of layer 1 as part of their study of the volume of area 46, and found no decrease in the thickness of layer 1 in Nissl stained sections with age, perhaps because of the lack of sharpness in laminar boundaries in the Nissl preparation.

According to a recent digitized neuronal density map analysis (Cruz et al., 2004), the neurons in area 46 are arranged in vertically oriented minicolumns that are each about 22 microns wide. A correlative in-depth morphological analysis has not been carried out, but it is likely that, as in other cortices, the apical dendrites of the pyramidal neurons in layers 5 through 2 are clustered together as they ascend through the cortex, and the myelinated efferent nerve fibers of the pyramidal neurons are aggregated into bundles as they descend towards the white matter [e.g., see (Peters, 1996)]. The digitized density map probably reflects the dimensions of the center-to-center spacing between the apical dendritic clusters. Cruz et al. (Cruz et al., 2004) also report that with increasing age the integrity of the minicolumns is compromised, because statistically there is significant decrease in the "strength" of minicolumns, indicating that neurons are being randomly displaced by as much as $3 \mu \mathrm{m}$. Interestingly this change significantly correlates with age-related cognitive decline.

\section{Unique connections of the subsectors of area $\mathbf{4 6}$}

The cognitive functions of area 46 are likely supported by the rich projections it receives from a host of cortical and subcortical structures, as highlighted here. The major sources of monosynaptic connections of area 46 are from other cortical areas. Area 46 is connected with unimodal visual, auditory and somatosensory association cortices but not directly with olfactory cortices. The different sectors of area 46 are differentially connected with each of the above association cortices, as highlighted below and in Figure 2. 


\section{Connections with visual and visuomotor cortices}

One of the major sources of connections of area 46 is the visual cortical association system, which involves specifically the caudal and ventral part of area 46 (Jones and Powell, 1970; Chavis and Pandya, 1976; Jacobson and Trojanowski, 1977; Barbas and Mesulam, 1985; Barbas, 1988; Webster et al., 1994), originate mostly from the inferior temporal cortex (areas TE2-3, TEa and TEm), and to a lesser extent from areas V4, V3, TEO and MT (Barbas and Mesulam, 1985; Barbas, 1988; Webster et al., 1994), in connections that are reciprocal (Rempel-Clower and Barbas, 2000). Caudal area 46 is also strongly connected with the lateral (ventral) bank of the intraparietal sulcus, which has visual and visuomotor properties (Barbas, 1988; Medalla and Barbas, 2006). These rich connections appear to be critical in cognitive operations and in orienting to visual stimuli that are relevant to the task at hand (Savaki and Dalezios, 1999; Moschovakis et al., 2004). Moreover, area 46 and the ventral intraparietal cortex are co-activated in visuomotor functions (Friedman and Goldman-Rakic, 1994).

\section{Connections with auditory association cortices}

Area 46, involving mostly its caudal half, is bidirectionally connected with superior temporal auditory association areas Ts2-3 and TAa, which overlap with areas known as the parabelt (Barbas and Mesulam, 1985; Petrides and Pandya, 1988; Hackett et al., 1999; Romanski et al., 1999a). A mid-dorsal part of area 46 is a major focus of connections with auditory association areas (Barbas and Mesulam, 1985; Hackett et al., 1999; Romanski et al., 1999b), as well as the dorsal part of rostral area 46 , which receives projections from auditory association areas Ts1Ts3 and Tpt (Petrides and Pandya, 1999), in pathways that are reciprocal (Medalla et al., 2007). The projections from prefrontal areas to auditory association areas may provide the circuit for selecting relevant auditory information and suppressing distracters, through association with laminar-specific neurochemical and functional classes of inhibitory neurons in auditory association cortex (Barbas et al., 2005; Medalla et al., 2007). Behavioral findings indicate that humans with dorsolateral prefrontal lesions make more errors in auditory discrimination tasks, specifically in the presence of distracting stimuli (Chao and Knight, 1998). Similar findings are reported for aged humans, suggesting that changes in the pathway from dorsolateral prefrontal cortex to auditory association cortex compromise the ability to ignore irrelevant signals (Chao and Knight, 1997).

\section{Connections with somatosensory cortices}

Another major source of cortical connections is from somatosensory association cortices, directed to the central part of ventral area 46 (Jones and Powell, 1970; Chavis and Pandya, 1976; Barbas and Mesulam, 1985; Barbas, 1988; Preuss and Goldman-Rakic, 1989; Cavada and Goldman-Rakic, 1989). The principal sources within somatosensory cortex include rostral intraparietal area PF (or area 7b), area SII, and areas 1 and 2 (Petrides and Pandya, 1984; Barbas and Mesulam, 1985; Cavada and Goldman-Rakic, 1989; Cipolloni and Pandya, 1999; Lewis and Van Essen, 2000). Sparse projections from the superior parietal lobule (area PE) terminate in the posterior half of dorsal area 46 (Petrides and Pandya, 1984; Morecraft et al., 2004), as do projections from the medial part of area 7 (Cavada and Goldman-Rakic, 1989). The rostro-ventral part of area 46 receives projections from the gustatory region, as well as from somatosensory areas 1, 2 and SII in the pericentral operculum (Cipolloni and Pandya, 1999).

\section{Connections with polymodal areas}

Area 46 is also connected with polymodal areas, including the upper (medial) bank of the superior temporal sulcus, where neurons respond to auditory, visual and/or somatosensory stimuli (Seltzer and Pandya, 1978). Throughout its extent, area 46 has bidirectional connections 
with these polymodal temporal cortices (Barbas and Mesulam, 1985; Barbas, 1988; Seltzer and Pandya, 1989; Petrides and Pandya, 1999).

\section{Connections of area 46 within the prefrontal cortices}

Area 46 is also connected monosynaptically with neighboring prefrontal cortices, possibly gaining access to signals that do not reach its individual sectors directly. Rostral area 46 is connected with frontal polar area 10 (Carmichael and Price, 1996), particularly its dorsal sector (Barbas and Mesulam, 1985; Barbas and Pandya, 1989), and with area 9 (Barbas and Mesulam, 1985; Barbas and Pandya, 1989), where it targets both excitatory and inhibitory neurons (Medalla and Barbas, 2009). Ventral area 46 is also innervated by area 9 (Pucak et al., 1996; Melchitzky et al., 1998). The caudal sector of area 46 has extensive bidirectional connections with adjacent area 8 (Barbas and Mesulam, 1981; Preuss and Goldman-Rakic, 1985; Barbas, 1988; Barbas and Pandya, 1989). Ventral area 46 has bidirectional connections with area 12 and orbitofrontal area 11 (Barbas and Mesulam, 1985; Barbas, 1988; Barbas and Pandya, 1989).

\section{Connections with limbic cortices}

Area 46 has significant connections with cortical limbic structures, broadly associated with memory processes, emotions, and the internal milieu. The strongest connections with limbic cortices are with the cingulate cortex. The rostral half of area 46 is connected with anterior cingulate area 32 (Barbas and Mesulam, 1985; Barbas, 1988; Barbas and Pandya, 1989), and the rostral part of area 24; the latter has weak connections with caudal area 46. Caudal area 24 is connected with almost the entire extent of area 46 (Baleydier and Mauguiere, 1980; Morecraft and Van Hoesen, 1993; Arikuni et al., 1994). The interaction of area 46 with the anterior cingulate, and adjacent areas 10 and 9, appears to be important in tasks with high cognitive demands [reviewed in (Paus, 2001; Taylor et al., 2007; Walton et al., 2007)]. The anterior and dorsal parts of area 46 have bidirectional connections with the posterior cingulate as well (area 23) (Baleydier and Mauguiere, 1980; Pandya et al., 1981; Morecraft et al., 2004). Some of the cingulate sites within areas 24 and 23 are part of the cingulate motor areas, as described below.

A significant source of connections of area 46 includes areas associated with the hippocampal system, though not the hippocampus proper (the subiculum and ammonic fields do not project to area 46). These cortical areas include the retrosplenial cortex (areas 29 and 30), as well as the presubiculum and parasubiculum, which project robustly to the caudal tip of dorsal area 46, the neighboring gyral cortex ventrally, and the mid-dorsal part of the principal sulcus (Barbas and Blatt, 1995; Parvizi et al., 2006; Kobayashi and Amaral, 2007), in pathways that are reciprocal (Selemon and Goldman-Rakic, 1988; Morris et al., 1999a). Area 30 projects to the rostral half of area 46 (Kobayashi and Amaral, 2007). These medial temporal areas have been referred to as the caudomedial lobule (Goldman-Rakic et al., 1984). The parahippocampal area TF sends moderate projections to the depths of the principal sulcus at the middle rostrocaudal extent of area 46 (Lavenex et al., 2002), in pathways that are reciprocal (Suzuki and Amaral, 1994), and issues sparse projections to caudal area 46 (Lavenex et al., 2002). The central part of area 46 sends moderate or sparse projections to parahippocampal areas TF and TH (Suzuki and Amaral, 1994). The relatively robust linkage of area 46 with retrosplenial cortices has been interpreted as evidence that these structures have a role in working memory (Morris et al., 1999b). An equally plausible explanation is that area 46 accesses information from areas involved in long-term memory in order to complete the task at hand, such as remembering where kitchen utensils are stored in the process of preparing a meal.

Area 46 has light and bidirectional connections with the amygdala (Aggleton et al., 1980; Ghashghaei et al., 2007), a structure associated with emotional processes. The projections from 
the amygdala to the caudal part of area 46 originate in the dorsal part of the basolateral nucleus, which receives projections from visual association cortices [for discussion and review of relevant literature see (Barbas and De Olmos, 1990)].

\section{Connections with premotor cortices}

Area 46 is strategically positioned for action in cognitive operations through its robust connections with most premotor areas, including the dorsal and ventral premotor cortex, as well as rostral and ventral cingulate motor areas, the SMA and pre-SMA (Selemon and Goldman-Rakic, 1988; McGuire et al., 1991; Bates and Goldman-Rakic, 1993; Lu et al., 1994; Wang et al., 2001; Hatanaka et al., 2003; Tachibana et al., 2004; Takada et al., 2004). Projections from area 46 target specifically the forelimb representation within the rostral and caudal cingulate motor areas (Bates and Goldman-Rakic, 1993). Moreover, area 46 is interlinked with sites that represent the entire arm in the ventral premotor area (Lu et al., 1994). Ventral area 46, in particular, is the only prefrontal area that has substantial projections to the digit representation within the ventral premotor area (Dum and Strick, 2005). In addition, area 46 has bidirectional connections with the larynx area, which is also situated in ventral area 6 (Simonyan and Jurgens, 2005). The dorsal sector of area 46 projects to several cingulate motor areas, including area $23 \mathrm{c}$ and area $24 \mathrm{c}$, but only its caudal sector projects sparsely to M2 (Morecraft and Van Hoesen, 1993).

\section{Connections with the thalamus}

The subsectors of area 46 have in common robust bidirectional connections with the mediodorsal thalamic nucleus, concentrated predominantly in its parvicellular division [e.g., (Giguere and Goldman-Rakic, 1988; Siwek and Pandya, 1991; Barbas et al., 1991; Erickson and Lewis, 2004)]. A minority of thalamic connections include the medial pulvinar, the ventral anterior, intralaminar and anterior nuclei (Gutierrez et al., 2000; Trojanowski and Jacobson, 1977; Barbas et al., 1991; Romanski et al., 1997; Xiao and Barbas, 2002; Xiao and Barbas, 2004; Xiao et al., 2009). Neurons in the mediodorsal thalamic nucleus, like those in area 46, fire when monkeys keep information on line during the delay period of the delayed response tasks (Alexander and Fuster, 1973; Fuster and Alexander, 1973), and their response is disrupted when cooling incapacitates area 46 (Alexander and Fuster, 1973). This evidence demonstrates the intricate relationship of the bidirectional corticothalamic pathways in a task that requires mnemonic processing on a temporary basis (Kubota et al., 1972; Alexander and Fuster, 1973; Kubota et al., 1980; Wilson et al., 1993).

Recent findings have shown that area 46, like all other cortices, projects to the thalamic reticular nucleus, which is entirely inhibitory, and is thought to gate information between the thalamus and the cortex [reviewed in (Barbas and Zikopoulos, 2007; Zikopoulos and Barbas, 2007a). However, unlike most other prefrontal cortices, which project only to the anterior sector of the reticular nucleus, dorsal area 46 issues more widespread projections, reaching reticular sites that receive projections from visual, auditory, somatosensory and polymodal cortices. Moreover, these central and caudal sectors of the thalamic reticular nucleus have bidirectional connections with thalamic nuclei that are connected with sensory and polymodal cortices (Zikopoulos and Barbas, 2006). This evidence suggests that area 46 may be in a unique position to gate sensory input through the thalamic reticular nucleus to select behaviorally relevant stimuli and suppress distracters at a very early stage of processing [reviewed in (Barbas and Zikopoulos, 2007; Zikopoulos and Barbas, 2007a)]. 


\section{Neurotransmitter-specific projections to area $\mathbf{4 6}$ and age-related changes in neurotransmitters}

As with other cortical areas, an important source of projections to area 46 is from neurotransmitter-specific systems in the basal forebrain and the brainstem. Dopaminergic fibers originating in the ventral tegmental area (Porrino and Goldman-Rakic, 1982; Williams and Goldman-Rakic, 1998), reach all layers of area 46 but are densest in the deep part of layer 1 and the adjacent layer 2, and in layers 5-6 (Lewis et al., 1988; Berger et al., 1988; Smiley and Goldman-Rakic, 1993). Noradrenergic fibers, which originate from the locus coeruleus (Porrino and Goldman-Rakic, 1982), have a different laminar distribution than the other modulator systems. Noradrenergic fibers innervate all layers of area 46 but are most densely distributed in the middle cortical layers, including layer 5, the deep part of layer 3 and layer 4 (Lewis and Morrison, 1989). Cholinergic projections (assessed by labeling with choline acetyltransferase, the biosynthetic enzyme, or acetylcholinesterase, the degradative enzyme for acetylcholine) originate from the basal forebrain, and innervate lightly most layers of area 46, and moderately layers 1, 2 and the upper part of layer 3 (Mesulam et al., 1984; Lewis, 1991; Mrzljak et al., 1995; Ghashghaei and Barbas, 2001). The serotonergic (5-HT) system, which originates in the raphe nuclei (Porrino and Goldman-Rakic, 1982), moderately innervates layers 1 and 2, and lightly all other layers of area 46 (Smiley and Goldman-Rakic, 1996).

The neurotransmitter-specific systems have complex and complementary roles in the cognitive functions of area 46. For example, working memory functions depend on optimal levels of DA, resembling an inverted $U$ pattern, so that too little or too much DA impair working memory, whereas a level in between these extremes is optimal (Arnsten, 2006). The effects of DA on working memory appear to be mediated through D1 receptors (Sawaguchi and Goldman-Rakic, 1991), so that antagonists of D1 receptors, introduced in low levels by iontophoresis, improve memory field activity in area 46, whereas high doses inhibit neuronal firing (Williams and Goldman-Rakic, 1995).

The noradrenergic locus coeruleus shows varied levels of activity that correlate with behavioral states [(Usher et al., 1999); reviewed in (Aston-Jones et al., 1999; Aston-Jones and Cohen, 2005)]. Very low levels of activity are associated with poor performance on a discrimination task in monkeys. At higher levels, performance is optimal, and at very high levels performance decreases, resembling a classic inverted U function (Aston-Jones et al., 1999). In the monkey dorsolateral prefrontal cortex, specifically in area 46, norepinephrine has differential effects depending on the type of receptor activated. Activation of $\alpha 2 \mathrm{~A}$ receptors enhances working memory, while activation of $\alpha 1$ and $\beta 1$ receptors impairs working memory (Arnsten, 2001; Arnsten, 2006). Disturbance in the balance of the level of dopamine and norepinephrine may help explain the distractibility that occurs in attention deficit hyperactivity disorder (Arnsten and $\mathrm{Li}, 2005)$.

The neurotransmitter-specific systems are differentially affected in normally aging monkeys. Monkeys between 10 and 18 years of age exhibit a 50\% drop in dopamine levels in area 46, shown by biochemical measurement of dopamine and its metabolite HVA (Goldman-Rakic and Brown, 1981; Wenk et al., 1989). By contrast, D1 receptor binding is unaltered with age in the monkey area 46 (Moore et al., 2005). There is little or no reduction in norepinephrine or serotonin during normal aging in monkeys (Goldman-Rakic and Brown, 1981), however, receptor-binding studies have revealed a significant reduction in both alpha-1 and alpha-2 norepinephrine receptor binding with age in the superficial layers of area 46 (Moore et al., 2005). Further, administration of noradrenergic alpha- 2 receptor agonists to aged monkeys improves their performance on the Delayed Response task (Arnsten and Contant, 1992; Berridge et al., 1993). Recently it has also been demonstrated that a beta- 2 agonist enhances 
working memory in aged monkeys (Ramos et al., 2008). Interestingly, monoamine receptor binding has a significant negative linear relationship with performance on DNMS, DRST and CSST (Moore et al., 2005). There is also evidence that serotonin and serotonin receptors are down regulated with age: in particular 5HT, 5HT1 and 5HT2 receptors are reported to be reduced in area 46 in aged monkeys (Goldman-Rakic and Brown, 1981; Wenk et al., 1989; Bigham and Lidow, 1995).

The cholinergic system plays an important role in learning and memory and has been the focus of numerous studies, but there is a lack of clarity and consistency in data on the effects of aging on this neurotransmitter system. For example, one study reported a modest reduction in ChAT levels in the frontal pole of aged rhesus monkeys (Wenk et al., 1989), but a subsequent study reported that the levels of this synthetic enzyme were not changed in the frontal cortex in a different cohort of aged monkeys (Wenk et al., 1991). Further, another study reported that neither M1 nor nicotinic ACh receptors are reduced with age in monkey prefrontal cortex (Wenk et al., 1989) while a subsequent study reported a significant decrease in M1 receptor binding in area 46 (Vannucchi and Goldman-Rakic, 1991). Clearly further work is required to unequivocally demonstrate whether cholinergic systems are substantially changed with age in the primate area 46.

Finally, there is evidence that both glutamatergic and GABAergic transmitter systems are altered with age in the neocortex. With regard to the glutamatergic system, this evidence includes findings of dendritic regression and loss of dendritic spines, the principal postsynaptic substrates for glutamate action (Jacobs et al., 1997; Page et al., 2002; Duan et al., 2003), a decrease in the number of neurons expressing glutamatergic GluR2 and NMDAR1 receptor subunits (Hof et al., 2002), and a significant decrease in the number of asymmetric synapses in area 46 (Peters et al., 2008a). Finally, there is a significant increase in binding density for the benzodiazepine receptor modulatory site on the $\mathrm{GABA}_{\mathrm{A}}$ receptor in the neocortex of aged monkeys, without a change in the binding density of $\mathrm{GABA}_{\mathrm{A}}$ receptors (Rosene and Nicholson, 1999).

\section{Age-related alterations in the morphology of neurons}

In Nissl stained sections of both monkey and human cortices it can be seen that aging neurons acquire some lipofuscin in their cell bodies, but in this type of preparation there are no other obvious alterations of neurons. However, when Golgi preparations, neuronal tracers, or intracellular filling are employed, a different picture emerges.

Some of the most comprehensive studies of the effects of age on neurons have been carried out by injecting tracers into area 46 and then examining the labeled cortico-cortical projection neurons in the temporal cortex [e.g., (Page et al., 2002; Duan et al., 2003)]. These studies have shown that when young and old monkeys are compared, there are only minor qualitative differences in the dendritic lengths and complexity of dendritic trees of the pyramidal neurons, but there is extensive loss of dendritic spines from all portions of the dendritic tree. Overall, there is a loss of some 25\% of dendritic spines on apical and basal dendrites (Duan et al., 2003). A similar observation was made in a later study that examined the effects of normal aging on the structural properties of layer $2 / 3$ pyramidal neurons in area 46 from rhesus monkeys (Kabaso et al., 2007). In addition to reduced branch lengths in the apical dendrites and increased numbers of segments in the basal dendrites, the aged neurons had reduced numbers of dendritic spines, amounting to 50\%, with fewer thin and more stubby spines being evident (Kabaso et al., 2007). Since thin and small spines are important for learning, the shift from thin to stubby spines may contribute to the learning deficits that occur during aging. In a recent study Kabaso et al. (2009) have shown that not all pyramidal neurons in the cortex are affected in the same way by age. Thus Kabaso et al. (2009) find that although all pyramidal 
cells lose spines, the dendrites of the long projecting neurons from superior temporal cortex to area 46 become shorter and less branched, while the lengths of dendrites of locally projecting pyramidal cells in area 46 are largely unaltered.

These recent studies on monkey cortex largely confirm earlier work on the effects of age on neurons in monkey prefrontal cortex (Cupp and Uemura, 1980). Examination of Golgi impregnated neurons revealed that with age entire branches are lost from the apical dendrites of pyramidal neurons, accompanied by a loss of about $25 \%$ of dendritic spines from all branches of the dendritic trees. By contrast, another study of Golgi impregnated neurons from prefrontal area 10 and visual area 18 of young and old human cerebral cortices concluded that with age there is only a slight loss in the overall extent of the dendritic trees of pyramidal neurons but a dramatic loss of about 50\% of dendritic spines (Jacobs et al., 1997).

The loss of spines on area 46 pyramidal neurons during normal aging in the monkey is paralleled by a loss of synapses. Electron microscopic analyses of the numerical density of both asymmetric (excitatory) and symmetric (inhibitory) synapses in the neuropil of layer 2/3 and layer 5 of behaviorally tested rhesus monkeys reveal that with age there is no change in the length of the synaptic junctions, or in the percentage distribution of synapses relative to postsynaptic spines and dendritic shafts (Peters et al., 2008a). However, in layer $2 / 3$ there is a loss of about $30 \%$ of synapses with age and both asymmetric and symmetric synapses are lost at the same rate. Layer 5 is different, since only about $20 \%$ of synapses are lost with age, and this is almost entirely due to a loss of asymmetric (excitatory) synapses. As far as we are aware, the only other study of the effects of aging on synapses in monkey prefrontal cortex is that of Uemura (Uemura, 1980), who used electron microscopy to examine superior frontal cortex, or area 9 , which is situated above area 46 and has related functions. The overall loss of synapses calculated in this study (Uemura, 1980) is similar to that of Peters et al. (Peters et al., 2008a), who also found loss of synapses from the upper and middle thirds of the depth of the cortex to be greater $(25 \%)$ than from the lower third $(16 \%)$.

A piecewise analysis of the data brought to light the interesting fact that most of the synapse loss occurs after 20 years of age. When the synapse loss data are correlated with the cognitive status of the monkeys, it emerges that for layer $2 / 3$ there is a strong correlation between cognitive impairment and the numerical density of asymmetric synapses and a weaker correlation between symmetric synapse loss and cognitive impairment. In contrast, for layer 5 there is no correlation between synapse loss and cognitive impairment.

The greatest loss of synapses (30-60\%) is found in layer 1, which becomes significantly thinner during aging (Peters et al., 1998b). The loss of synapses in layer 1 is accompanied by a reduction in the frequency of profiles of dendrites and dendritic spines. In layer 1 there is a significant correlation between the numerical density of synapses and the cognitive decline exhibited by aged monkeys. Interestingly, although there is a similar thinning of layer 1 in area 17 of the monkey cortex, accompanied by a loss of dendritic branches, dendritic spines and synapses, these alterations do not correlate with behavioral changes in memory function. The probable basis for this difference is that while area 46 is implicated in cognition, the same is unlikely to be true of area 17 (Peters et al., 2001a).

The extensive loss of synapses from layer 1 of area 46 with age is very interesting in light of the fact that there is a massive input of thalamic afferents from the $\mathrm{M}$ (matrix) neurons in thalamic nuclei to layer 1 of cerebral cortex in several species [reviewed in (Jones, 2007)]. Moreover, inputs from several thalamic nuclei in rats converge on layer 1 throughout the cerebral cortex (Rubio-Garrido et al., 2009). These findings are consistent with the strong projections from most thalamic nuclei to layer 1 in monkeys, which run in parallel to the classically described thalamic projection system to the middle layers of the cortex [reviewed 
in (Jones, 1998; Jones, 2007)]. Recent studies show that in rhesus monkeys there is a significant projection from the ventral anterior thalamic nucleus to the entire prefrontal cortex, including area 46 (Zikopoulos and Barbas, 2007b). In addition to projections to the middle layers, significant projections from the ventral anterior thalamic nucleus reach layer 1 of area 46 and the adjacent area 9 (Zikopoulos and Barbas, 2007b). The large majority of these projections originate from calbindin positive 'matrix' thalamic neurons. It is highly probable that there is a similar input to layer 1 of area 46 by other thalamic nuclei in the monkey. The reduction in the number of dendritic branches and synapses from the apical tufts would interfere with the feedback interactions between area 46 and thalamic nuclei, which appear to be crucial for associative learning and attention.

The results of electron microscopic analyses of aging and synapse numbers in human frontal cortex are much more confusing. For example, Scheff et al. (Scheff et al., 2001) examined layers 3 and 5 in area 9 from the brains of cognitively normal humans and concluded that during the first eight decades of life there is no significant loss of synapses. These findings support a similar conclusion reached earlier by another group, who examined synapses in layer 3 of frontal cortex (Huttenlocher, 1979). In contrast, another study reported a significant loss of synapses with age from human frontal, but not temporal cortex, in brains from "apparently intellectually normal people". Interestingly, when these brains were compared with ones from patients diagnosed as suffering from Alzheimer type dementia, the numbers of synapses in the two groups were similar (Gibson, 1983). The results of determining synapse numbers in the frontal cortices of human brains using antibodies, such as ones against synaptophysin, to label axon terminals are also conflicting. For example, several studies found that individuals older than 60 years showed an average of $20 \%$ decrease in the numbers of synapses in the frontal cortex compared to young individuals (Masliah et al., 1993). By contrast, a fourth study found no loss of synapses (Zhan et al., 1993).

Since there is a loss of dendritic spines from pyramidal neurons in non-human primate frontal cortex with aging, it follows that there has to be a loss of synapses involving these spines. Why disagreement has arisen about whether there is a loss of synapses from human frontal cortex with normal aging is not clear, but various authors have attributed the discrepant findings to factors such as the inadvertent inclusion of patients with early stages of Alzheimer's disease among the normal subjects, morphological changes brought about by long postmortem intervals, and inappropriate methods used to make accurate synaptic counts.

\section{Age-related changes in nerve fibers and in myelin}

MRI studies of both monkeys [e.g., (Lai et al., 1995b)] and humans [e.g., (Albert, 1993; Guttmann et al., 1998)] have shown a loss of white matter from the cerebral hemispheres with age, and especially from the frontal lobes. To determine how much of a loss of nerve fibers from monkey white matter occurs with age, several fiber tracts have been examined by electron microscopy. These tracts include the anterior commissure (Sandell and Peters, 2003), the optic nerve (Sandell and Peters, 2001), as well as the fornix, the splenium of the corpus callosum and the anterior cingulate bundle (unpublished data). In each of these tracts there is a significant loss of myelinated nerve fibers ( 20 to $40 \%$ ) with age. Any loss of white matter must result in some disconnection between various components of the central nervous system. Of the tracts for which there is information on both the extent of nerve fiber loss and the cognitive status of the monkeys, there are significant correlations between the two measures for the fornix, and anterior commissure, but not for the splenium of the corpus callosum or for the cingulate bundle. However, for the cingulate bundle there is a significant correlation between cognition and the frequency of myelinated nerve fiber profiles and degenerating axons (M. Bowley: personal communication). This is of interest since the cingulate bundle is a heterogeneous tract 
that connects the prefrontal cortex, the thalamus, striatum, cingulate gyrus, parietal cortex and medial temporal lobe (Mufson and Pandya, 1984; Schmahmann and Pandya, 2006).

Although there is substantial loss of myelinated nerve fibers from white matter in aging primates [e.g., (Peters et al., 2000; Peters, 2007)], only few appear to be lost from cortical gray matter. However, there are age-related changes in the structure of myelin sheaths in both white and gray matter of the cerebral hemispheres [e.g., (Feldman and Peters, 1998; Peters et al., 2000; Peters and Sethares, 2002a)], since some nerve fibers show degenerative alterations (Fig. 3). These alterations include focal splitting of the sheaths to accommodate dense cytoplasm of the oligodendrocytes that form the sheaths, and ballooning of sheaths by accumulation of fluid in splits of myelin sheaths (Fig. 3). There is reason to believe that these degenerative changes are due to the degeneration and death of oligodendrocytes.

Other age-related myelin alterations are considered to be regenerative. One is the thickening of sheaths by addition of myelin lamellae, especially to the sheaths of larger diameter fibers (Peters et al., 2001b), and another is the formation of sheaths that contain redundant myelin, so that the loose sheaths are much too large for the size of the ensheathed axons.

When the frequency of occurrence of these age-related alterations in myelin are assessed in area 46 of rhesus monkeys, it is found that they increase significantly in frequency with age. The frequency of occurrence of profiles of sheaths that show myelin alterations also correlates significantly with the cognitive impairment shown by the monkeys (Peters and Sethares, 2002a). It is likely that myelin defects slow down the rate of conduction along the nerve fibers, so that the timing in neuronal circuits is affected.

Another alteration in myelin sheaths in area 46 is a $90 \%$ age-related increase in the frequency of occurrence of profiles of paranodes, indicating an increase in the numbers of internodal lengths of myelin with age (Peters and Sethares, 2003). This increase would occur if some of the original lengths of myelin degenerate and are replaced by shorter internodes with thinner myelin sheaths. Indeed, shorter internodal lengths of myelin and abnormally thin myelin sheaths have been found in the cortices of old monkeys (Peters and Sethares, 2003). The increase in paranodal profiles in area 46 correlates significantly with both age and cognitive impairment, and it has been suggested that the correlation with impairment occurs because of an increase in the number of internodes, and hence the number of nodes of Ranvier along nerve fibers, which slows conduction speed. This conclusion fits with earlier reports of a reduced conduction velocity along myelinated nerve fibers in the spinal cord of old compared to young cats (Morales et al., 1987). More directly, the slowing of conduction velocity by the interposition of short internodal lengths on conduction velocity has also been demonstrated directly in the rubrospinal tract of the mouse as it remyelinates following a crush lesion (Lasiene et al., 2008). It should also be pointed out that with aging there is some reorganization of nodes of Ranvier in monkey central nervous system (Hinman et al., 2006). As some sheaths become thicker with age, the paranodal loops become disorganized, so that not all of them reach the axon to form membranous junctions. There are also alterations in the molecular organization of this region, because with age the voltage- dependent potassium channels normally present in the juxtaparanodal region become mislocalized to the paranodal regions, and this may be detrimental to the maintenance of axonal conduction. No comparable studies are available for human brains, since obtaining human material that is well enough preserved to carry out such studies is extremely difficult.

\section{Age-related changes in neuroglial cells}

With increasing age, astrocytes, oligodendrocytes and microglial cells accumulate some inclusions in their perikarya. This is especially true of the astrocytes, which in normal aging appear to be the primary phagocytes in the cerebral cortices of primates. What material is being 
phagocytosed by astrocytes has not been fully determined, but it is clear that they do phagocytose degenerating myelin sheaths, since pieces of myelin sheaths are sometimes evident within astrocytes, and some of the more amorphous inclusions can be labeled with antibodies to myelin basic protein (Peters and Sethares, 2003). Although astrocytes become more fibrous with age, there is no evidence that they hypertrophy, other than in layer 1 . The glial limiting membrane becomes thicker in layer 1 and astrocytes enlarge to fill the spaces in the neuropil produced by degeneration of portions of the apical dendritic trees of pyramidal neurons. Astrocytes also become more filamentous (Bandler et al., 1991). However, there is no increase in the number of astrocytes in layer 1 of area 46 with age (Peters and Sethares, 2002b). Microglia also contain inclusions in aging monkeys, but surprisingly they do not normally seem to be involved in phagocytosing degenerating myelin, since there is no convincing evidence that any of the inclusions in microglia are labeled with antibodies to myelin basic protein (Peters and Sethares, 2003); the same is true of the inclusions in oligodendrocytes.

Recently, we have examined the effects of age on the populations of neuroglial cells in primary visual cortex (Peters and Sethares, 2004; Peters et al., 2008b) and in area 46 (unpublished data). While there are no changes with age in the numbers of astrocytes and microglial cells, there is a 45 to $50 \%$ increase in the numbers of oligodendrocytes. Oligodendrocyte number does not correlate with cognitive impairment, but it does correlate with the age-related increase in the numbers of profiles of paranodes of myelinated nerve fibers. This evidence suggests that increased numbers of oligodendrocytes are required to produce the shorter internodal lengths that are associated with remyelination.

As pointed out in the previous section, there is strong evidence that some myelin internodes degenerate with age, probably due to the degeneration of their parent oligodendrocytes, which may be reflected by the formation of bulbous enlargements along the processes of some oligodendrocytes in older monkeys. These processes are filled with characteristic inclusions [see (Peters et al., 1991; Peters, 1996)], which are akin to those found within the cell bodies of oligodendrocytes in the cerebral cortices of older monkeys. However, it has yet to be established that these inclusions are a sign of oligodendrocyte degeneration.

There is no information available for primates, but in adult rodents some oligodendrocytes normally die with age while others are generated and it is the imbalance between these two processes that leads to the increase in the numbers of oligodendrocytes with age (Cerghet et al., 2006). It is possible that newly generated oligodendrocytes are derived by division of existing oligodendrocytes, which would explain the presence of groups of oligodendrocytes in the aging cerebral cortex. However it is much more likely that new oligodendrocytes are derived from the oligodendroglial progenitor cells. These progenitor cells are recognized by the fact that they label with antibodies to the platelet-derived growth factor $\alpha$ receptor PDGFRA/NG2. Such cells are distributed throughout the adult central nervous system and it has recently been shown that in adult mice these precursor cells generate oligodendrocytes that are capable of myelinating axons (Rivers et al., 2008). It is likely that this is also true in the monkey, since NG2 labeled cells have been identified in monkey cerebral cortex [see (Peters, 2004; Peters and Sethares, 2004)]. Interestingly, when such precursor cells are examined in the electron microscope they closely resemble protoplasmic astrocytes, which may help explain why they were overlooked in early studies of the fine structure of cerebral cortex.

\section{Age-related changes in the electrophysiological properties of layer 3 and layer $\mathbf{5}$ pyramidal neurons in area $\mathbf{4 6}$ of the rhesus monkey}

As discussed above, there is abundant evidence that individual pyramidal neurons in area 46 of the rhesus monkey undergo significant structural changes during normal aging. It is well 
established by experimental and theoretical modeling studies that the structural properties of a given neuron play a critical role (together with connectional and intrinsic ion channel properties) in determining its electrophysiological properties. Specifically, dendritic and somatic structural properties determine the passive electrotonic properties of a given neuron. In turn, the electrotonic properties are fundamental determinants of synaptic integration and neural firing patterns (Mainen and Sejnowski, 1996; Euler and Denk, 2001; Vetter et al., 2001; Krichmar et al., 2002; Weaver and Wearne, 2008). Thus, the significant age-related changes in neuronal structure described above - dendritic regression, loss of dendritic spines and synapses, and myelin dystrophy, in particular - would be expected to have a major impact on the functional properties of individual neurons. For example, one might plausibly predict that dendritic regression would lead to increased input resistance with concomitant increases in excitability, or that significant loss of dendritic spines would lead to a decrease in the frequency and amplitude of glutamatergic excitatory synaptic responses. Indeed, most studies have hypothesized that the significant structural alterations to neurons that occur with age are likely to have significant and detrimental functional consequences. In view of the mounting evidence of structural changes in neurons in primates, the dearth of studies on the effects of aging on the electrophysiological properties of neurons is striking. To our knowledge, to date only two in vivo studies have examined the effects of aging on the electrophysiological properties of neocortical neurons in the monkey. In these, Leventhal and coworkers demonstrated that visual cortical neurons in aged monkeys exhibit significantly increased spontaneous action potential (AP) firing rates, and that these alterations are associated with degradation of visual stimulus selectivity (Schmolesky et al., 2000; Leventhal et al., 2003). These tantalizing findings highlight the need for similar studies to be performed in the prefrontal cortex of cognitively characterized young, middle-aged and old rhesus monkeys which are an excellent model for humans, in which neither in vivo nor in vitro electrophysiological experiments such as those described here are possible.

Over the past several years we have begun to examine the effects of age on neuronal function in the non-human primate by recording from pyramidal neurons in in vitro slices prepared from area 46 of behaviorally characterized young and aged rhesus monkeys. In this series of studies, whole cell patch clamp recordings have been used to assess the basic electrophysiological properties of both layer 3 (primarily cortico-cortical) and layer 5 (primarily cortico-striatal) pyramidal neurons (Luebke et al., 2004; Chang et al., 2005; Chang and Luebke, 2006; Luebke and Chang, 2007). As a result, we have demonstrated that fundamental electrophysiological properties of layer 3 , but not layer 5 , pyramidal neurons are significantly changed with age, and that these changes are associated with cognitive performance within the aged cohort of monkeys from which slices were prepared.

\section{Passive membrane properties}

The passive membrane properties of a neuron are its resting membrane potential, membrane time constant and input resistance. These passive properties (determined by the structural membrane characteristics) play a determinative role in the entire repertoire of electrophysiological features of a given neuron, including AP firing rates and patterns, presynaptic activity and postsynaptic responses. As an example, neurons having high input resistance will, under normal conditions, respond to a given depolarizing input with a larger membrane potential change (greater depolarization, or increased excitability) than a cell with low input resistance. Because passive properties are integral to the electrophysiological phenotype of all neurons, determination of the effects of normal aging on these properties is of paramount importance, particularly in light of the known age-related changes in the structure of area 46 pyramidal neurons in the monkey. The resting membrane potential and time constant of both layer 3 and layer 5 pyramidal neurons in area 46 are unaltered with age, while the input resistance of layer 3, but not layer 5, pyramidal neurons is significantly increased (Chang et 
al., 2005; Luebke and Chang, 2007). The basis for this increase in input resistance of layer 3 pyramidal neurons remains to be determined, but, as described below, the increase is associated with a significant, functionally important increase in the excitability of these neurons in in vitro slices of area 46.

\section{Repetitive AP firing properties}

The most functionally relevant age-related alteration in electrophysiological properties observed in area 46 of the monkey to date is a dramatic increase in the frequency of AP firing of layer 3, but not layer 5, pyramidal neurons (Chang et al., 2005; Luebke and Chang, 2007). For example, the mean frequency of APs elicited in layer 3 pyramidal neurons by a 2 second $180 \mathrm{pA}$ depolarizing current step is almost two times greater in old, as compared to young monkeys. Interestingly, there is a significant positive linear relationship between firing rate and input resistance, indicating that increased input resistance is a significant contributor to increased firing rate. It is possible that age-related alterations in the ionic currents responsible for the timing of spike trains play an important role in the observed increase in excitability of aged layer 3 pyramidal neurons. An increase in excitatory synaptic inputs, or a decrease in inhibitory synaptic inputs could also plausibly contribute to increased firing rates. However, the evidence (discussed below) for significantly decreased excitatory and increased inhibitory synaptic responses in layer 3 pyramidal neurons of prefrontal cortex from aged monkeys (Luebke et al., 2004) is not consistent with this idea.

\section{Excitatory and inhibitory synaptic response properties of layer 3 pyramidal neurons in area 46 of aged monkeys}

Normal aging results in a dramatic loss of dendritic spines and of synapses in layer 3 pyramidal neurons of the prefrontal cortex (discussed above). The significant loss of this postsynaptic substrate suggests that there will be significant changes in the glutamatergic synaptic response properties of these neurons. Indeed, whole cell patch clamp recordings have demonstrated that spontaneous excitatory postsynaptic currents (sEPSCs) in layer 3 neurons are significantly reduced in frequency with age (Luebke et al., 2004). These changes could be due to a loss of dendritic spines and synapses, or to a reduction in the release of glutamate from presynaptic terminals. Given the clear evidence for increased, not reduced, excitability of layer 3 pyramidal neurons, which provide a majority of the glutamatergic input to each other in normal aging, we favor the first idea (Chang et al., 2005). On the other hand, the amplitude and kinetics of miniature excitatory PSCs are not significantly altered with age. This evidence suggests that AMPA receptors present on the remaining spines are not significantly altered with age. In marked contrast to EPSCs, the frequency of $\mathrm{GABA}_{\mathrm{A}}$ receptor-mediated spontaneous inhibitory PSCs are significantly increased with age in layer 3 pyramidal neurons (Luebke et al., 2004). This finding is somewhat paradoxical in view of the finding that symmetric synapses are reduced in this brain area with age (Peters et al., 2008a). Perhaps the most straightforward explanation for the increase in spontaneous inhibitory PSC frequency is an increase in the action potential-dependent release of GABA from presynaptic interneurons; however this hypothesis has yet to be directly tested. As with excitatory synaptic events, the frequency, amplitude, and kinetics of miniature inhibitory PSCs are not significantly different in neurons in young and old monkeys, indicating that the properties of the $\mathrm{GABA}_{\mathrm{A}}$ receptor per se and the GABA release probability are not markedly altered with age in these cells.

\section{Implications of age-related electrophysiological changes for age-related decline in cognitive functions mediated by the prefrontal cortex in non-human primates}

The series of electrophysiological studies described here have yielded several findings of relevance to an understanding of the neural basis of age-related decline in executive function mediated by area 46 in monkeys. In a broad sense, one of the most interesting findings is the 
significant change in the electrophysiological properties of layer 3 pyramidal neurons with age, while layer 5 pyramidal neurons are relatively spared. This is interesting in light of the fact that area 46 projects to other cortices primarily from layer 3 (Barbas and Rempel-Clower, 1997), and layer 3 neurons are thought to play a more central role in the cognitive abilities mediated by area 46 than layer 5 neurons, which project largely to the striatum. The second key finding is that firing rates of layer 3 pyramidal neurons are significantly changed in slices prepared from aged monkeys, and that these rates are related, in a U-shaped manner, to the cognitive performance of the monkeys from which the slices were prepared. Across all behavioral tasks, AP firing rates assessed in vitro are significantly related to the performance of the aged monkeys, such that the cells with the lowest and highest firing rates were from slices prepared from monkeys that exhibited poor performance while those with intermediate firing rates were from slices prepared from monkeys that exhibited good performance. This suggests that performance is dependent on a precise pattern of neural activity, such that firing rates that are too low are insufficient to differentiate relevant signals from background noise, and firing rates that are too high result in increased "noise." Such U-shaped relationships are not unusual in biological systems. These findings are consistent with the idea that there is an optimal firing rate in aged monkeys that has a higher frequency than in young monkeys. Such a shift may plausibly be a compensatory response to increased AP conduction failure (Rosene et al., 2003) secondary to the extensive myelin dystrophy seen in the primate prefrontal cortex with age (reviewed in (Peters, 2002)). Thus in the aged prefrontal cortex, higher rates of firing may be required to maintain functions that are encoded by lower rates in the young prefrontal cortex.

\section{Conclusions}

Table 1 and Figure 4 summarize what is currently known about the effects of age on area 46 in monkeys. Senile plaques, although few in number in the rhesus monkey cortex, do become more frequent with age, but the increase has no correlation with cognitive decline. Other parameters, such as volume of the gray matter and the number of neurons per unit volume, do not appear to change significantly to any extent, and so these factors are also unlikely to be the basis of cognitive decline. However, analysis of digitized images suggests that the arrangement of neurons into microcolumns becomes somewhat disorganized with increasing age, and this does correlate with cognitive decline, although the reason is not known. Whether there is an age-related decrease in the overall thickness of area 46 is still debatable. However, there is thinning of layer 1 with age. This is associated with loss of dendrites and synapses from the apical tufts of pyramidal neurons, which correlate with the DNMS behavioral test with a 2 minute delay. Layer 1 has a significant role in the function of cortical columns, as recipient of the dendrites from pyramidal neurons in the cortical layers below [reviewed in (Vogt, 1991)]. In addition, layer 1 is enriched with inputs from external sources, and receives significant projections from subcortical neurotransmitter-specific systems, from the matrix (calbindinspecific) system of the thalamus, and from cortico-cortical feedback projections.

Other than the effects on their apical tufts with age, pyramidal neurons in area 46 lose some of their other dendrites, and some dendrites are shortened. Importantly, as many as 25 to $50 \%$ of dendritic spines are lost with age, paralleled by an overall loss of both excitatory and inhibitory synapses from the neuropil. In layer $2 / 3$ the loss of as many as $30 \%$ of synapses with age correlates significantly with cognitive decline. However, the biggest loss of synapses is in layer 1 (30 to 60\%), affecting mostly the apical dendritic tufts of pyramidal neurons. As is the case with layers $2 / 3$, there is a correlation between synapse loss from layer 1 and cognitive decline. In contrast to the upper layers of the cortex, loss of synapses from layer 5 is only about $20 \%$ and does not correlate with cognitive decline. The origins of the axon terminals that formed these lost synapses are not known, since they could be from either intrinsic or extrinsic sources. However since the intrinsic excitatory neurons provide at least $90 \%$ of the axospinous 
synapses in the cortex it is likely that they are the primary source of axospinous synapses that are lost with age. The loss of inhibitory synapses must be from the axonal plexuses of intrinsic inhibitory neurons, since the available evidence shows that inhibitory input in primates arises overwhelmingly from intrinsic sources at the level of cortical columns (Melchitzky et al., 2001).

Since there is a ubiquitous loss of white matter with age, and white matter contains the extrinsic myelinated nerve fibers that interconnect areas of the cortex with each other, it is highly likely that the extrinsic inputs to area 46 are reduced with age. It would follow that with age area 46 becomes partially disconnected. As for transmitters, it is known that there is a decrease in dopamine levels in area 46 with age, and a decrease in norepinephrine, serotonin and acetylcholine receptors. Further studies are needed to examine the effects of these age-related decreases in transmitter and receptor levels on cognition, since altering the levels of these extrinsic transmitters can affect behavioral performance.

With increasing age, many of the sheaths of the myelinated nerve fibers in both white and gray matter degenerate, so that many of the nerve fibers lose their original myelin sheaths and become remyelinated by shorter internodes with thinner sheaths. Both the increase in number of degenerating myelin sheaths and paranodes, and hence the increase in the number of internodal lengths of myelin correlate with cognitive decline. It is suggested that both the degeneration of sheaths and the formation of shorter internodes leads to a reduction in conduction velocity, so that the timing in neuronal circuits is affected, leading to cognitive impairment.

What is becoming clear from studies of area 46 and other cortical areas is that there is no single factor responsible for the cognitive decline associated with aging. For example, loss of nerve fibers from white matter results in some disconnections between parts of the central nervous system, reductions in the synaptic inputs to neurons alter the intrinsic physiological properties of neurons, and alterations in myelin sheaths result in reductions in conduction velocity so that the timing of neuronal circuits is affected (Fig. 4). At present we have only a general map to indicate the direction in which further studies should go. We hope that future research will fill in some of the details and lead to effective interventions in retarding the effects of cognitive decline which affects our increasingly aging population.

\section{Acknowledgments}

We thank Maria Medalla and Basilis Zikopoulos for help with Figure 1 and Figure 2. Original work by the authors was supported by NIH grants NIH grants from NIA, NCRR (J.L. and A.P.), NINDS and NIMH, and CELEST, an NSF Science of Learning Center (H.B.).

\section{References}

Aggleton JP, Burton MJ, Passingham RE. Cortical and subcortical afferents to the amygdala of the rhesus monkey (Macaca mulatta). Brain Res 1980;190:347-368. [PubMed: 6768425]

Albert M. Neuropsychological and neurophysiological changes in healthy adult humans across the age range. Neurobiol. Aging 1993;14:623-625. [PubMed: 8295666]

Alexander GE, Chen K, Aschenbrenner M, Merkley TL, Santerre-Lemmon LE, Shamy JL, Skaggs WE, Buonocore MH, Rapp PR, Barnes CA. Age-related regional network of magnetic resonance imaging gray matter in the rhesus macaque. J. Neurosci 2008;28:2710-2718. [PubMed: 18337400]

Alexander GE, Fuster JM. Effects of cooling prefrontal cortex on cell firing in the nucleus medialis dorsalis. Brain Res 1973;61:93-105. [PubMed: 4204131]

Arikuni T, Sako H, Murata A. Ipsilateral connections of the anterior cingulate cortex with the frontal and medial temporal cortices in the macaque monkey. Neurosci. Res 1994;21:19-39. [PubMed: 7535904] 
Arnsten AF. Modulation of prefrontal cortical-striatal circuits: relevance to therapeutic treatments for Tourette syndrome and attention-deficit hyperactivity disorder. Adv. Neurol 2001;85:333-341. [PubMed: 11530441]

Arnsten AF. Fundamentals of attention-deficit/hyperactivity disorder: circuits and pathways. J. Clin. Psychiatry 2006;67:7-12. [PubMed: 16961424]

Arnsten AF, Contant TA. Alpha-2 adrenergic agonists decrease distractibility in aged monkeys performing the delayed response task. Psychopharmacology (Berl) 1992;108:159-169. [PubMed: 1357704]

Arnsten AF, Li BM. Neurobiology of executive functions: catecholamine influences on prefrontal cortical functions. Biol. Psychiatry 2005;57:1377-1384. [PubMed: 15950011]

Aston-Jones G, Cohen JD. An integrative theory of locus coeruleus-norepinephrine function: adaptive gain and optimal performance. Annu. Rev. Neurosci 2005;28:403-450. [PubMed: 16022602]

Aston-Jones G, Rajkowski J, Cohen J. Role of locus coeruleus in attention and behavioral flexibility. Biol. Psychiatry 1999;46:1309-1320. [PubMed: 10560036]

Baleydier C, Mauguiere F. The duality of the cingulate gyrus in monkey. Neuroanatomical study and functional hypothesis. Brain 1980;103:525-554. [PubMed: 6774795]

Bandler R, Carrive P, Zhang SP. Integration of somatic and autonomic reactions within the midbrain periaqueductal grey: viscerotopic, somatotopic and functional organization. Prog. Brain Res 1991;87:269-305. [PubMed: 1678189]

Barbas H. Anatomic organization of basoventral and mediodorsal visual recipient prefrontal regions in the rhesus monkey. J. Comp. Neurol 1988;276:313-342. [PubMed: 3192766]

Barbas H, Blatt GJ. Topographically specific hippocampal projections target functionally distinct prefrontal areas in the rhesus monkey. Hippocampus 1995;5:511-533. [PubMed: 8646279]

Barbas H, De Olmos J. Projections from the amygdala to basoventral and mediodorsal prefrontal regions in the rhesus monkey. J. Comp. Neurol 1990;301:1-23. [PubMed: 1706353]

Barbas H, Henion TH, Dermon CR. Diverse thalamic projections to the prefrontal cortex in the rhesus monkey. J. Comp. Neurol 1991;313:65-94. [PubMed: 1761756]

Barbas H, Medalla M, Alade O, Suski J, Zikopoulos B, Lera P. Relationship of prefrontal connections to inhibitory systems in superior temporal areas in the rhesus monkey. Cereb. Cortex 2005;15:13561370. [PubMed: 15635060]

Barbas H, Mesulam MM. Organization of afferent input to subdivisions of area 8 in the rhesus monkey. J. Comp. Neurol 1981;200:407-431. [PubMed: 7276245]

Barbas H, Mesulam MM. Cortical afferent input to the principalis region of the rhesus monkey. Neuroscience 1985;15:619-637. [PubMed: 4069349]

Barbas H, Pandya DN. Architecture and intrinsic connections of the prefrontal cortex in the rhesus monkey. J. Comp. Neurol 1989;286:353-375. [PubMed: 2768563]

Barbas H, Rempel-Clower N. Cortical structure predicts the pattern of corticocortical connections. Cereb. Cortex 1997;7:635-646. [PubMed: 9373019]

Barbas H, Zikopoulos B. The prefrontal cortex and flexible behavior. Neuroscientist 2007;13:532-545. [PubMed: 17901261]

Bartus RT, Dean RL III, Fleming DL. Aging in the rhesus monkey: effects on visual discrimination learning and reversal learning. J. Gerontol 1979;34:209-219. [PubMed: 108323]

Bates JF, Goldman-Rakic PS. Prefrontal connections of medial motor areas in the rhesus monkey. J. Comp. Neurol 1993;336:211-228. [PubMed: 7503997]

Berger B, Trottier S, Verney C, Gaspar P, Alvarez C. Regional and laminar distribution of the dopamine and serotonin innervation in the macaque cerebral cortex: a radioautographic study. J. Comp. Neurol 1988;273:99-119. [PubMed: 3209731]

Berridge CW, Arnsten AF, Foote SL. Noradrenergic modulation of cognitive function: clinical implications of anatomical, electrophysiological and behavioural studies in animal models [editorial]. Psychol. Med 1993;23:557-564. [PubMed: 8234565]

Bigham MH, Lidow MS. Adrenergic and serotonergic receptors in aged monkey neocortex. Neurobiol. Aging 1995;16:91-104. [PubMed: 7723941] 
Carlson S, Rama P, Tanila H, Linnankoski I, Mansikka H. Dissociation of mnemonic coding and other functional neuronal processing in the monkey prefrontal cortex. J. Neurophysiol 1997;77:761-774. [PubMed: 9065848]

Carmichael ST, Price JL. Connectional networks within the orbital and medial prefrontal cortex of macaque monkeys. J. Comp. Neurol 1996;371:179-207. [PubMed: 8835726]

Cavada C, Goldman-Rakic PS. Posterior parietal cortex in rhesus monkey: II. Evidence for segregated corticocortical networks linking sensory and limbic areas with the frontal lobe. J. Comp. Neurol 1989;287:422-445. [PubMed: 2477406]

Cerghet M, Skoff RP, Bessert D, Zhang Z, Mullins C, Ghandour MS. Proliferation and death of oligodendrocytes and myelin proteins are differentially regulated in male and female rodents. J. Neurosci 2006;26:1439-1447. [PubMed: 16452667]

Chang Y, Luebke JI. Age-related increase in the slow outward calcium-activated potassium current in layer 3 and layer 5 pyramidal cells in area 46 of the rhesus monkey. J. Neurophysiol 2006;98:26222632. [PubMed: 17804579]

Chang YM, Rosene DL, Killiany RJ, Mangiamele LA, Luebke JI. Increased action potential firing rates of layer $2 / 3$ pyramidal cells in the prefrontal cortex are significantly related to cognitive performance in aged monkeys. Cereb. Cortex 2005;15:409-418. [PubMed: 15749985]

Chao LL, Knight RT. Prefrontal deficits in attention and inhibitory control with aging. Cereb. Cortex 1997;7:63-69. [PubMed: 9023433]

Chao LL, Knight RT. Contribution of human prefrontal cortex to delay performance. J. Cogn. Neurosci 1998;10:167-177. [PubMed: 9555105]

Chavis DA, Pandya DN. Further observations on corticofrontal connections in the rhesus monkey. Brain Res 1976;117:369-386. [PubMed: 825194]

Cipolloni PB, Pandya DN. Cortical connections of the frontoparietal opercular areas in the rhesus monkey. J. Comp. Neurol 1999;403:431-458. [PubMed: 9888311]

Cruz L, Roe DL, Urbanc B, Cabral H, Stanley HE, Rosene DL. Age-related reduction in microcolumnar structure in area 46 of the rhesus monkey correlates with behavioral decline. Proc. Natl. Acad. Sci. U. S. A 2004;101:15846-15851. [PubMed: 15520373]

Cupp CJ, Uemura E. Age-related changes in prefrontal cortex of Macaca mulatta: quantitative analysis of dendritic branching patterns. Exp. Neurol 1980;69:143-163. [PubMed: 6771151]

Dombrowski SM, Hilgetag CC, Barbas H. Quantitative architecture distinguishes prefrontal cortical systems in the rhesus monkey. Cereb. Cortex 2001;11:975-988. [PubMed: 11549620]

Duan H, Wearne SL, Rocher AB, Macedo A, Morrison JH, Hof PR. Age-related dendritic and spine changes in corticocortically projecting neurons in macaque monkeys. Cereb. Cortex 2003;13:950961. [PubMed: 12902394]

Dum RP, Strick PL. Frontal lobe inputs to the digit representations of the motor areas on the lateral surface of the hemisphere. J. Neurosci 2005;25:1375-1386. [PubMed: 15703391]

Erickson SL, Lewis DA. Cortical connections of the lateral mediodorsal thalamus in cynomolgus monkeys. J. Comp. Neurol 2004;473:107-127. [PubMed: 15067722]

Euler T, Denk W. Dendritic processing. Curr. Opin. Neurobiol 2001;11:415-422. [PubMed: 11502386]

Feldman ML, Peters A. Ballooning of myelin sheaths in normally aged macaques. J. Neurocytol 1998;27:605-614. [PubMed: 10405027]

Fisk JE, Sharp CA. Age-related impairment in executive functioning: updating, inhibition, shifting, and access. J. Clin. Exp. Neuropsychol 2004;26:874-890. [PubMed: 15742539]

Friedman HR, Goldman-Rakic PS. Coactivation of prefrontal cortex and inferior parietal cortex in working memory tasks revealed by $2 \mathrm{DG}$ functional mapping in the rhesus monkey. J. Neurosci 1994;14:2775-2788. [PubMed: 8182439]

Funahashi S, Bruce CJ, Goldman-Rakic PS. Dorsolateral prefrontal lesions and occulomotor delayedresponse performance: Evidence for mnemonic "scotomas". J. Neurosci 1993;13:1479-1497. [PubMed: 8463830]

Funahashi S, Takeda K. Information processes in the primate prefrontal cortex in relation to working memory processes. Rev. Neurosci 2002;13:313-345. [PubMed: 12542260]

Fuster, JM. The Prefrontal Cortex. New York: Raven Press; 1989. 
Fuster JM. Frontal lobes. Curr. Opin. Neurobiol 1993;3:160-165. [PubMed: 8513226]

Fuster JM, Alexander GE. Firing changes in cells of the nucleus medialis dorsalis associated with delayed response behavior. Brain Res 1973;61:79-91. [PubMed: 4204130]

Gearing M, Tigges J, Mori H, Mirra SS. A beta40 is a major form of beta-amyloid in nonhuman primates. Neurobiol. Aging 1996;17:903-908. [PubMed: 9363802]

Ghashghaei HT, Barbas H. Neural interaction between the basal forebrain and functionally distinct prefrontal cortices in the rhesus monkey. Neuroscience 2001;103:593-614. [PubMed: 11274781]

Ghashghaei HT, Hilgetag CC, Barbas H. Sequence of information processing for emotions based on the anatomic dialogue between prefrontal cortex and amygdala. Neuroimage 2007;34:905-923. [PubMed: 17126037]

Gibson PH. EM study of the numbers of cortical synapses in the brains of ageing people and people with Alzheimer-type dementia. Acta Neuropathol 1983;62:127-133. [PubMed: 6659870]

Giguere M, Goldman-Rakic PS. Mediodorsal nucleus: Areal, laminar, and tangential distribution of afferents and efferents in the frontal lobe of rhesus monkeys. J. Comp. Neurol 1988;277:195-213. [PubMed: 2466057]

Goldman-Rakic PS. Topography of cognition: Parallel distributed networks in primate association cortex. Annu. Rev. Neurosci 1988;11:137-156. [PubMed: 3284439]

Goldman-Rakic PS, Brown RM. Regional changes of monoamines in cerebral cortex and subcortical structures of aging rhesus monkeys. Neuroscience 1981;6:177-187. [PubMed: 6111765]

Goldman-Rakic PS, Selemon LD, Schwartz ML. Dual pathways connecting the dorsolateral prefrontal cortex with the hippocampal formation and parahippocampal cortex in the rhesus monkey. Neuroscience 1984;12:719-743. [PubMed: 6472617]

Gutierrez C, Cola MG, Seltzer B, Cusick C. Neurochemical and connectional organization of the dorsal pulvinar complex in monkeys. J. Comp. Neurol 2000:61-86. [PubMed: 10717640]

Guttmann CR, Jolesz FA, Kikinis R, Killiany RJ, Moss MB, Sandor T, Albert MS. White matter changes with normal aging. Neurology 1998;50:972-978. [PubMed: 9566381]

Hackett TA, Stepniewska I, Kaas JH. Prefrontal connections of the parabelt auditory cortex in macaque monkeys. Brain Res 1999;817:45-58. [PubMed: 9889315]

Hatanaka N, Tokuno H, Hamada I, Inase M, Ito Y, Imanishi M, Hasegawa N, Akazawa T, Nambu A, Takada M. Thalamocortical and intracortical connections of monkey cingulate motor areas. J. Comp. Neurol 2003;462:121-138. [PubMed: 12761828]

Heilbroner PL, Kemper TL. The cytoarchitectonic distribution of senile plaques in 3 aged monkeys. Acta Neuropathol 1990;81:60-65. [PubMed: 1707575]

Herndon JG, Moss MB, Rosene DL, Killiany RJ. Patterns of cognitive decline in aged rhesus monkeys. Behav. Brain Res 1997;87:25-34. [PubMed: 9331471]

Hinman JD, Peters A, Cabral H, Rosene DL, Hollander W, Rasband MN, Abraham CR. Age-related molecular reorganization at the node of Ranvier. J. Comp. Neurol 2006;495:351-362. [PubMed: 16485288]

Huttenlocher PR. Synaptic density in human frontal cortex - developmental changes and effects of aging. Brain Res 1979;163:195-205. [PubMed: 427544]

Jacobs B, Driscoll L, Schall M. Life-span dendritic and spine changes in areas 10 and 18 of human cortex: a quantitative Golgi study. J. Comp. Neurol 1997;386:661-680. [PubMed: 9378859]

Jacobsen CF. Studies of cerebral function in primates: I. The functions of the frontal association area in monkeys. Comp. Psychol. Monogr 1936;13:3-60.

Jacobson S, Trojanowski JQ. Prefrontal granular cortex of the rhesus monkey I. Intrahemispheric cortical afferents. Brain Res 1977;132:209-233. [PubMed: 407975]

Jones EG. A new view of specific and nonspecific thalamocortical connections. Adv. Neurol 1998;77:4971. [PubMed: 9709817]

Jones, EG. The thalamus. New York: Cambridge University Press; 2007.

Jones EG, Powell TPS. An anatomical study of converging sensory pathways within the cerebral cortex of the monkey. Brain 1970;93:793-820. [PubMed: 4992433] 
Kabaso D, Weaver CM, Rocher AB, Luebke JI, Wearne SL. Contributions to the age-related changes in dendrites and spine geometry to increased excitability in neurons of the prefrontal cortex of monkeys. Neuroscience Abstracts 37. 2007 Ref Type: Abstract.

Kabaso D, Coskren PJ, Henry BJ, Hof PR, Wearne SL. The electrotonic structure of pyramidal neurons contributing to prefrontal cortical circuits in macaque monkeys is signficantly altered with age. Cerebrl. Cortex 2009;19:2238-2268.

Kanemaru K, Iwatsubo T, Ihara Y. Comparable amyloid beta-protein (A beta) 42(43) and A beta 40 deposition in the aged monkey brain. Neurosci. Lett 1996;214:196-198. [PubMed: 8878117]

Kobayashi Y, Amaral DG. Macaque monkey retrosplenial cortex: III. Cortical efferents. J. Comp. Neurol 2007;502:810-833. [PubMed: 17436282]

Krichmar JL, Nasuto SJ, Scorcioni R, Washington SD, Ascoli GA. Effects of dendritic morphology on CA3 pyramidal cell electrophysiology: a simulation study. Brain Res 2002;941:11-28. [PubMed: 12031543]

Kubota K, Niki H, Goto A. Thalamic unit activity and delayed alternation performance in the monkey. Acta Neurobiol. Exp. (Warsz) 1972;32:177-192. [PubMed: 4627613]

Kubota K, Tonoike M, Mikami A. Neuronal activity in the monkey dorsolateral prefrontal cortex during a discrimination task with delay. Brain Res 1980;183:29-42. [PubMed: 6766776]

Lai ZC, Moss MB, Killiany RJ, Rosene DL, Herndon JG. Executive system dysfunction in the aged monkey: spatial and object reversal learning. Neurobiol. Aging 1995a;16:947-954. [PubMed: 8622786]

Lai ZC, Rosene DL, Killiany RJ, Pugliese D, Albert MS, Moss MB. Age-related changes in the brain of the rhesus monkey: MRI changes in white matter but not in grey matter. Neurosci. Abstr 1995b; 21:1564.

Lasiene J, Shupe L, Perlmutter S, Horner P. No evidence for chronic demyelination in spared axons after spinal cord injury in a mouse. J. Neurosci 2008;28:3887-3896. [PubMed: 18400887]

Lavenex P, Suzuki WA, Amaral DG. Perirhinal and parahippocampal cortices of the macaque monkey: projections to the neocortex. J. Comp. Neurol 2002;447:394-420. [PubMed: 11992524]

Leventhal AG, Wang Y, Pu M, Zhou Y, Ma Y. GABA and its agonists improved visual cortical function in senescent monkeys. Science 2003;300:812-815. [PubMed: 12730605]

Lewis DA. Distribution of choline acetyltransferase-immunoreactive axons in monkey frontal cortex. Neuroscience 1991;40:363-374. [PubMed: 2027466]

Lewis DA, Foote SL, Goldstein M, Morrison JH. The dopaminergic innervation of monkey prefrontal cortex: A tyrosine hydroxylase immunohistochemical study. Brain Res 1988;449:225-243. [PubMed: 2899447]

Lewis DA, Morrison JH. Noradrenergic innervation of monkey prefrontal cortex: A dopamine- $\beta$ hydoxylase immunohistochemical study. J. Comp. Neurol 1989;282:317-330. [PubMed: 2715385]

Lewis JW, Van Essen DC. Corticocortical connections of visual, sensorimotor, and multimodal processing areas in the parietal lobe of the macaque monkey. J. Comp. Neurol 2000;428:112-137. [PubMed: 11058227]

Lu M, Preston JB, Strick PL. Interconnections Between the Prefrontal Cortex and the Premotor Areas in the Frontal Lobe. J. Comp. Neurol 1994;341:375-392. [PubMed: 7515081]

Luebke JI, Chang YM. Effects of aging on the electrophysiological properties of layer 5 pyramidal cells in the monkey prefrontal cortex. Neuroscience 2007;150:556-562. [PubMed: 17981400]

Luebke JI, Chang YM, Moore TL, Rosene DL. Normal aging results in decreased synaptic excitation and increased synaptic inhibition of layer $2 / 3$ pyramidal cells in the monkey prefrontal cortex. Neuroscience 2004;125:277-288. [PubMed: 15051166]

Mainen ZF, Sejnowski TJ. Influence of dendritic structure on firing pattern in model neocortical neurons. Nature 1996;382:363-366. [PubMed: 8684467]

Masliah E, Mallory M, Hansen L, DeTeresa R, Terry RD. Quantitative synaptic alterations in the human neocortex during normal aging. Neurology 1993;43:192-197. [PubMed: 8423884]

McGuire PK, Bates JF, Goldman-Rakic PS. Interhemispheric integration: I. symmetry and convergence of the corticocortical connections of the left and the right principal sulcus (PS) and the left and the right supplementary motor area (SMA) in the rhesus monkey. Cereb. Cortex 1991;1:390-407. [PubMed: 1726605] 
Medalla M, Barbas H. Diversity of laminar connections linking periarcuate and lateral intraparietal areas depends on cortical structure. Eur. J Neurosci 2006;23:161-179. [PubMed: 16420426]

Medalla M, Barbas H. Synapses with inhibitory neurons differentiate anterior cingulate from dorsolateral prefrontal pathways associated with cognitive control. Neuron 2009;61:609-620. [PubMed: 19249280]

Medalla M, Lera P, Feinberg M, Barbas H. Specificity in inhibitory systems associated with prefrontal pathways to temporal cortex in primates. Cereb. Cortex 2007;17:i136-i150. [PubMed: 17725996]

Melchitzky DS, Gonzalez-Burgos G, Barrionuevo G, Lewis DA. Synaptic targets of the intrinsic axon collaterals of supragranular pyramidal neurons in monkey prefrontal cortex. J. Comp. Neurol 2001;430:209-221. [PubMed: 11135257]

Melchitzky DS, Sesack SR, Pucak ML, Lewis DA. Synaptic targets of pyramidal neurons providing intrinsic horizontal connections in monkey prefrontal cortex. J. Comp. Neurol 1998;390:211-224. [PubMed: 9453665]

Mesulam MM, Rosen AD, Mufson EJ. Regional variations in cortical cholinergic innervation: Chemoarchitectonics of acetylcholinesterase-containing fibers in the macaque brain. Brain Res 1984;311:245-258. [PubMed: 6498483]

Moore TL, Killiany RJ, Herndon JG, Rosene DL, Moss MB. Impairment in abstraction and set shifting in aged rhesus monkeys. Neurobiol. Aging 2003;24:125-134. [PubMed: 12493558]

Moore TL, Killiany RJ, Herndon JG, Rosene DL, Moss MB. Executive system dysfunction occurs as early as middle-age in the rhesus monkey. Neurobiol. Aging 2006;27:1484-1493. [PubMed: 16183172]

Moore TL, Schettler SP, Killiany RJ, Herndon JG, Luebke JI, Moss MB, Rosene DL. Cognitive impairment in aged rhesus monkeys associated with monoamine receptors in the prefrontal cortex. Behav. Brain Res 2005;160:208-221. [PubMed: 15863218]

Morales FR, Boxer PA, Fung SJ, Chase MH. Basic electrophysiological properties of spinal cord motoneurons during old age in the cat. J. Neurophysiol 1987;58:180-194. [PubMed: 3612223]

Morecraft RJ, Cipolloni PB, Stilwell-Morecraft KS, Gedney MT, Pandya DN. Cytoarchitecture and cortical connections of the posterior cingulate and adjacent somatosensory fields in the rhesus monkey. J. Comp. Neurol 2004;469:37-69. [PubMed: 14689472]

Morecraft RJ, Van Hoesen GW. Frontal granular cortex input to the cingulate (M3), supplementary (M2) and primary (M1) motor cortices in the rhesus monkey. J. Comp. Neurol 1993;337:669-689. [PubMed: 8288777]

Morris R, Pandya DN, Petrides M. Fiber system linking the mid-dorsolateral frontal cortex with the retrosplenial/presubicular region in the rhesus monkey. J. Comp. Neurol 1999a;407:183-192. [PubMed: 10213090]

Morris R, Petrides M, Pandya DN. Architecture and connections of retrosplenial area 30 in the rhesus monkey (Macaca mulatta). Eur. J. Neurosci 1999b;11:2506-2518. [PubMed: 10383640]

Moschovakis AK, Gregoriou GG, Ugolini G, Doldan M, Graf W, Guldin W, Hadjidimitrakis K, Savaki HE. Oculomotor areas of the primate frontal lobes: a transneuronal transfer of rabies virus and [14C]-2-deoxyglucose functional imaging study. J. Neurosci 2004;24:5726-5740. [PubMed: 15215295]

Mrzljak L, Pappy M, Leranth C, Goldman-Rakic PS. Cholinergic synaptic circuitry in the macaque prefrontal cortex. J. Comp. Neurol 1995;357:603-617. [PubMed: 7673486]

Mufson EJ, Pandya DN. Some observations on the course and composition of the cingulum bunble in the rhesus monkey. J. Comp. Neurol 1984;225:31-43. [PubMed: 6725639]

O'Donnell KA, Rapp PR, Hof PR. Preservation of prefrontal cortical volume in behaviorally characterized aged macaque monkeys. Exp. Neurol 1999;160:300-310. [PubMed: 10630214]

Page TL, Einstein M, Duan H, He Y, Flores T, Rolshud D, Erwin JM, Wearne SL, Morrison JH, Hof PR. Morphological alterations in neurons forming corticocortical projections in the neocortex of aged Patas monkeys. Neurosci. Lett 2002;317:37-41. [PubMed: 11750991]

Pandya DN, Van Hoesen GW, Mesulam M-M. Efferent connections of the cingulate gyrus in the rhesus monkey. Exp. Brain Res 1981;42:319-330. [PubMed: 6165607]

Parvizi J, Van Hoesen GW, Buckwalter J, Damasio A. Neural connections of the posteromedial cortex in the macaque. Proc. Natl. Acad. Sci. U. S. A 2006;103:1563-1568. [PubMed: 16432221] 
Paus T. Primate anterior cingulate cortex: where motor control, drive and cognition interface. Nat. Rev. Neurosci 2001;2:417-424. [PubMed: 11389475]

Peters A, Moss MB, Sethares C. Effects of aging on myelinated nerve fibers on monkey primary visual cortex. J. Comp. Neurol 2000;419:364-376. [PubMed: 10723011]

Peters A. Age-related changes in oligodendrocytes in monkey cerebral cortex. J. Comp. Neurol 1996;371:153-163. [PubMed: 8835724]

Peters A. The effects of normal aging on myelin and nerve fibers: a review. J. Neurocytol 2002;31:581593. [PubMed: 14501200]

Peters A. A fourth type of neuroglial cell in the adult central nervous system. J. Neurocytol 2004;33:345357. [PubMed: 15475689]

Peters, A. The effects of normal aging on nerve fibers and neuroglia in the central nervous system. In: Riddle, DR., editor. Brain Aging: Models, Methods and Mechanisms. Baton Rouge: CRC press; 2007. p. 97-125.

Peters A, Josephson K, Vincent SL. Effects of aging on the neuroglial cells and pericytes within area 17 of the rhesus monkey cerebral cortex. Anat. Rec 1991;229:384-398. [PubMed: 2024779]

Peters A, Leahu D, Moss MB, McNally KJ. The effects of aging on area 46 of the frontal cortex of the rhesus monkey. Cereb. Cortex 1994;4:621-635. [PubMed: 7703688]

Peters A, Morrison JH, Rosene DL, Hyman BT. Are neurons lost from primate cerebral cortex during normal aging? Cereb. Cortex 1998a;8:295-300. [PubMed: 9651126]

Peters A, Moss MB, Sethares C. The effects of aging on layer 1 of primary visual cortex in the rhesus monkey. Cereb. Cortex 2001a;11:93-103. [PubMed: 11208664]

Peters A, Sethares C. Aging and the myelinated fibers in prefrontal cortex and corpus callosum of the monkey. J. Comp. Neurol 2002a;442:277-291. [PubMed: 11774342]

Peters A, Sethares C. The effects of age on the cells in layer 1 of primate cerebral cortex. Cereb. Cortex 2002b;12:27-36. [PubMed: 11734530]

Peters A, Sethares C. Is there remyelination during aging of the primate central nervous system? J. Comp. Neurol 2003;460:238-254. [PubMed: 12687688]

Peters A, Sethares C. Oligodendrocytes, their progenitors and other neuroglial cells in the aging primate cerebral cortex. Cereb. Cortex 2004;14:995-1007. [PubMed: 15115733]

Peters A, Sethares C, Killiany RJ. Effects of age on the thickness of myelin sheaths in monkey primary visual cortex. J. Comp. Neurol 2001b;435:241-248. [PubMed: 11391644]

Peters A, Sethares C, Luebke JI. Synapses are lost during aging in the primate prefrontal cortex. Neuroscience 2008a;152:970-981. [PubMed: 18329176]

Peters A, Sethares C, Moss MB. The effects of aging on layer 1 in area 46 of prefrontal cortex in the rhesus monkey. Cereb. Cortex 1998b;8:671-684. [PubMed: 9863695]

Peters A, Verderosa A, Sethares C. The neuroglial population in the primary visual cortex of the aging rhesus monkey. Glia 2008b;56:1151-1161. [PubMed: 18449941]

Petrides M, Pandya DN. Projections to the frontal cortex from the posterior parietal region in the rhesus monkey. J. Comp. Neurol 1984;228:105-116. [PubMed: 6480903]

Petrides M, Pandya DN. Association fiber pathways to the frontal cortex from the superior temporal region in the rhesus monkey. J. Comp. Neurol 1988;273:52-66. [PubMed: 2463275]

Petrides M, Pandya DN. Dorsolateral prefrontal cortex: comparative cytoarchitectonic analysis in the human and the macaque brain and corticocortical connection patterns. Eur. J Neurosci 1999;11:1011-1036. [PubMed: 10103094]

Porrino LJ, Goldman-Rakic PS. Brainstem innervation of prefrontal and anterior cingulate cortex in the rhesus monkey revealed by retrograde transport of HRP. J. Comp. Neurol 1982;205:63-76. [PubMed: 6121826]

Preuss TM, Goldman-Rakic PS. Somatosensory representation in primate prefrontal cortex: Connections of the principal sulcus with S-I, S-II, and adjacent areas of the frontoparietal operculum. Neurosci. Abstr 1985;11:677.

Preuss TM, Goldman-Rakic PS. Connections of the ventral granular frontal cortex of macaques with perisylvian premotor and somatosensory areas: Anatomical evidence for somatic representation in primate frontal association cortex. J. Comp. Neurol 1989;282:293-316. [PubMed: 2708598] 
Preuss TM, Goldman-Rakic PS. Myelo- and cytoarchitecture of the granular frontal cortex and surrounding regions in the strepsirhine primate Galago and the anthropoid primate Macaca. J. Comp. Neurol 1991;310:429-474. [PubMed: 1939732]

Pucak ML, Levitt JB, Lund JS, Lewis DA. Patterns of intrinsic and associational circuitry in monkey prefrontal cortex. J. Comp. Neurol 1996;376:614-630. [PubMed: 8978474]

Ramos BP, Colgan LA, Nou E, Arnsten AF. Beta2 adrenergic agonist, clenbuterol, enhances working memory performance in aging animals. Neurobiol. Aging 2008;29:1060-1069. [PubMed: 17363115]

Rapp PR. Visual discrimination and reversal learning in the aged monkey (Macaca mulatta). Behav. Neurosci 1990;104:876-884. [PubMed: 2285486]

Rempel-Clower NL, Barbas H. The laminar pattern of connections between prefrontal and anterior temporal cortices in the rhesus monkey is related to cortical structure and function. Cereb. Cortex 2000;10:851-865. [PubMed: 10982746]

Rhodes MG. Age-related differences in performance on the Wisconsin card sorting test: a meta-analytic review. Psychol. Aging 2004;19:482-494. [PubMed: 15382998]

Rivers LE, Young KM, Rizzi M, Jamen F, Psachoulia K, Wade A, Kessaris N, Richardson WD. PDGFRA/NG2 glia generate myelinating oligodendrocytes and piriform projection neurons in adult mice. Nat. Neurosci 2008;11:1392-1401. [PubMed: 18849983]

Rodriguez-Aranda C, Sundet K. The frontal hypothesis of cognitive aging: factor structure and age effects on four frontal tests among healthy individuals. J. Genet. Psychol 2006;167:269-287. [PubMed: 17278416]

Romanski LM, Bates JF, Goldman-Rakic PS. Auditory belt and parabelt projections to the prefrontal cortex in the rhesus monkey. J. Comp. Neurol 1999a;403:141-157. [PubMed: 9886040]

Romanski LM, Giguere M, Bates JF, Goldman-Rakic PS. Topographic organization of medial pulvinar connections with the prefrontal cortex in the rhesus monkey. J. Comp. Neurol 1997;379:313-332. [PubMed: 9067827]

Romanski LM, Tian B, Fritz J, Mishkin M, Goldman-Rakic PS, Rauschecker JP. Dual streams of auditory afferents target multiple domains in the primate prefrontal cortex. Nat. Neurosci 1999b;2:11311136. [PubMed: 10570492]

Rosene DL, Luebke JI, Mangiamele LA, Sandell JH, Peters A. Anatomical and physiological properties of the corpus callosum in the aged monkey. Neurosci. Abstr. 2003

Rosene, DL.; Nicholson, TJ. Some neurotranmitter receptor changes in the hippocampus and cerebral cortex in normal aging. In: Peters, A.; Morrison, JH., editors. Cerebral Cortex: Neurodegenerative and age-related changes in cerebral cortex. Vol. Vol. 14. New York: Kluwer Academic/Plenum Publishers; 1999. p. 111-128.

Rubio-Garrido P, Perez-de-Manzo F, Porrero C, Galazo MJ, Clasca F. Thalamic Input to Distal Apical Dendrites in Neocortical Layer 1 Is Massive and Highly Convergent. Cereb. Cortex 2009;19:23802395. [PubMed: 19188274]

Salthouse TA, Atkinson TM, Berish DE. Executive functioning as a potential mediator of age-related cognitive decline in normal adults. J. Exp. Psychol. Gen 2003;132:566-594. [PubMed: 14640849]

Sandell JH, Peters A. Effects of age on nerve fibers in the rhesus monkey optic nerve. J. Comp. Neurol 2001;429:541-553. [PubMed: 11135234]

Sandell JH, Peters A. Disrupted myelin and axon loss in the anterior commissure of the aged rhesus monkey. J. Comp. Neurol 2003;466:14-30. [PubMed: 14515238]

Savaki HE, Dalezios Y. 14C-deoxyglucose mapping of the monkey brain during reaching to visual targets. Prog. Neurobiol 1999;58:473-540. [PubMed: 10408655]

Sawaguchi T, Goldman-Rakic PS. D1 dopamine receptors in prefrontal cortex: involvement in working memory. Science 1991;251:947-950. [PubMed: 1825731]

Scheff SW, Price DA, Sparks DL. Quantitative assessment of possible age-related change in synaptic numbers in the human frontal cortex. Neurobiol. Aging 2001;22:355-365. [PubMed: 11378240]

Schmahmann, JD.; Pandya, DN. Fiber pathways of the brain. New York: Oxford University Press Inc.; 2006.

Schmolesky MT, Wang Y, Pu M, Leventhal AG. Degradation of stimulus selectivity of visual cortical cells in senescent rhesus monkeys. Nat. Neurosci 2000;3:384-390. [PubMed: 10725929] 
Selemon LD, Goldman-Rakic PS. Common cortical and subcortical targets of the dorsolateral prefrontal and posterior parietal cortices in the rhesus monkey: Evidence for a distributed neural network subserving spatially guided behavior. J. Neurosci 1988;8:4049-4068. [PubMed: 2846794]

Seltzer B, Pandya DN. Afferent cortical connections and architectonics of the superior temporal sulcus and surrounding cortex in the rhesus monkey. Brain Res 1978;149:1-24. [PubMed: 418850]

Seltzer B, Pandya DN. Frontal lobe connections of the superior temporal sulcus in the rhesus monkey. J. Comp. Neurol 1989;281:97-113. [PubMed: 2925903]

Simonyan K, Jurgens U. Afferent cortical connections of the motor cortical larynx area in the rhesus monkey. Neuroscience 2005;130:133-149. [PubMed: 15561431]

Siwek DF, Pandya DN. Prefrontal projections to the mediodorsal nucleus of the thalamus in the rhesus monkey. J. Comp. Neurol 1991;312:509-524. [PubMed: 1761739]

Sloane JA, Pietropaolo MF, Rosene DL, Moss MB, Peters A, Kemper T, Abraham CR. Lack of correlation between plaque burden and cognition in the aged monkey. Acta Neuropathol 1997;94:471-478. [PubMed: 9386780]

Smiley JF, Goldman-Rakic PS. Heterogeneous targets of dopamine synapses in monkey prefrontal cortex demonstrated by serial section electron microscopy: a laminar analysis using the silver-enhanced diaminobenzidine sulfide (SEDS) immunolabeling technique. Cereb. Cortex 1993;3:223-238. [PubMed: 7686795]

Smiley JF, Goldman-Rakic PS. Serotonergic axons in monkey prefrontal cerebral cortex synapse predominantly on interneurons as demonstrated by serial section electron microscopy. J. Comp. Neurol 1996;367:431-443. [PubMed: 8698902]

Smith DE, Rapp PR, McKay HM, Roberts JA, Tuszynski MH. Memory impairment in aged primates is associated with focal death of cortical neurons and atrophy of subcortical neurons. J. Neurosci 2004;24:4373-4381. [PubMed: 15128851]

Sorel O, Pennequin V. Aging of the planning process: the role of executive functioning. Brain Cogn 2008;66:196-201. [PubMed: 17884265]

Steere JC, Arnsten AF. The alpha-2A noradrenergic receptor agonist guanfacine improves visual object discrimination reversal performance in aged rhesus monkeys. Behav. Neurosci 1997;111:883-891. [PubMed: 9383511]

Struble RG, Price DL Jr, Cork LC, Price DL. Senile plaques in cortex of aged normal monkeys. Brain Res 1985;361:267-275. [PubMed: 4084799]

Suzuki WA, Amaral DG. Perirhinal and parahippocampal cortices of the macaque monkey: Cortical afferents. J. Comp. Neurol 1994;350:497-533. [PubMed: 7890828]

Tachibana Y, Nambu A, Hatanaka N, Miyachi S, Takada M. Input-output organization of the rostral part of the dorsal premotor cortex, with special reference to its corticostriatal projection. Neurosci. Res 2004;48:45-57. [PubMed: 14687880]

Takada M, Nambu A, Hatanaka N, Tachibana Y, Miyachi S, Taira M, Inase M. Organization of prefrontal outflow toward frontal motor-related areas in macaque monkeys. Eur. J Neurosci 2004;19:33283342. [PubMed: 15217388]

Taylor SF, Stern ER, Gehring WJ. Neural systems for error monitoring: recent findings and theoretical perspectives. Neuroscientist 2007;13:160-172. [PubMed: 17404376]

Tigges J, Gordon TP, McClure HM, Hall EC, Peters A. Survival rate and life span of rhesus monkeys at the Yerkes Regional Primate Research Center. Am. J. Primatol 1988;15:263-273.

Trojanowski JQ, Jacobson S. The morphology and laminar distribution of cortico-pulvinar neurons in the rhesus monkey. Exp. Brain Res 1977;28:51-62. [PubMed: 407094]

Uemura E. Age-related changes in prefrontal cortex of Macaca mulatta: synaptic density. Exp. Neurol 1980;69:164-172. [PubMed: 6771152]

Usher M, Cohen JD, Servan-Schreiber D, Rajkowski J, Aston-Jones G. The role of locus coeruleus in the regulation of cognitive performance. Science 1999;283:549-554. [PubMed: 9915705]

Vannucchi MG, Goldman-Rakic PS. Age-dependent decrease in the affinity of muscarinic M1 receptors in neocortex of rhesus monkeys. Proc. Natl. Acad. Sci. U. S. A 1991;88:11475-11479. [PubMed: 1763062]

Vetter P, Roth A, Hausser M. Propagation of action potentials in dendrites depends on dendritic morphology. J. Neurophysiol 2001;85:926-937. [PubMed: 11160523] 
Vogt, BA. The role of layer 1 in cortical function. In: Peters, A., editor. Cerebral Cortex. Vol. Vol. 9. New York: Plenum Publishing Corp.; 1991. p. 49-79.

Voytko ML. Impairments in acquisition and reversals of two-choice discriminations by aged rhesus monkeys. Neurobiol. Aging 1999;20:617-627. [PubMed: 10674427]

Walker AE. A cytoarchitectural study of the prefrontal area of the macaque monkey. J. Comp. Neurol 1940;73:59-86.

Walton ME, Croxson PL, Behrens TE, Kennerley SW, Rushworth MF. Adaptive decision making and value in the anterior cingulate cortex. Neuroimage 2007;36:T142-T154. [PubMed: 17499161]

Wang Y, Shima K, Sawamura H, Tanji J. Spatial distribution of cingulate cells projecting to the primary, supplementary, and pre-supplementary motor areas: a retrograde multiple labeling study in the macaque monkey. Neurosci. Res 2001;39:39-49. [PubMed: 11164252]

Weaver CM, Wearne SL. Neuronal firing sensitivity to morphologic and active membrane parameters. PLoS Comput. Biol 2008;4:e11. [PubMed: 18208320]

Webster MJ, Bachevalier J, Ungerleider LG. Connections of inferior temporal areas TEO and TE with parietal and frontal cortex in macaque monkeys. Cereb. Cortex 1994;4:470-483. [PubMed: 7530521]

Wenk GL, Pierce DJ, Struble RG, Price DL, Cork LC. Age-related changes in multiple neurotransmitter systems in the monkey brain. Neurobiol. Aging 1989;10:11-19. [PubMed: 2569169]

Wenk GL, Walker LC, Price DL, Cork LC. Loss of NMDA, but not GABA-A, binding in the brains of aged rats and monkeys. Neurobiol. Aging 1991;12:93-98. [PubMed: 1646968]

Williams GV, Goldman-Rakic PS. Modulation of memory fields by dopamine D1 receptors in prefrontal cortex [see comments]. Nature 1995;376:572-575. [PubMed: 7637804]

Williams SM, Goldman-Rakic PS. Widespread origin of the primate mesofrontal dopamine system. Cereb. Cortex 1998;8:321-345. [PubMed: 9651129]

Wilson FA, Scalaidhe SP, Goldman-Rakic PS. Dissociation of object and spatial processing domains in primate prefrontal cortex. Science 1993;260:1955-1958. [PubMed: 8316836]

Xiao D, Barbas H. Pathways for emotions and memory II. afferent input to the anterior thalamic nuclei from prefrontal, temporal, hypothalamic areas and the basal ganglia in the rhesus monkey. Thalamus and Related Systems 2002;2:33-48.

Xiao D, Barbas H. Circuits through prefrontal cortex, basal ganglia, and ventral anterior nucleus map pathways beyond motor control. Thalamus \& Related Systems 2004;2:325-343.

Xiao D, Zikopoulos B, Barbas H. Laminar and modular organization of prefrontal projections to multiple thalamic nuclei. Neuroscience 2009;161:1067-1081. [PubMed: 19376204]

Zhan SS, Beyreuther K, Schmitt HP. Quantitative assessment of the synaptophysin immuno-reactivity of the cortical neuropil in various neurodegenerative disorders with dementia. Dementia 1993;4:6674. [PubMed: 8358515]

Zikopoulos B, Barbas H. Prefrontal projections to the thalamic reticular nucleus form a unique circuit for attentional mechanisms. J. Neurosci 2006;26:7348-7361. [PubMed: 16837581]

Zikopoulos B, Barbas H. Circuits for multisensory integration and attentional modulation through the prefrontal cortex and the thalamic reticular nucleus in primates. Rev. Neurosci 2007a;18:417-438. [PubMed: 18330211]

Zikopoulos B, Barbas H. Parallel Driving and Modulatory Pathways Link the Prefrontal Cortex and Thalamus. PLoS One 2007b;2:e848. doi:10.1371/journal.pone.0000848. [PubMed: 17786219] 
A

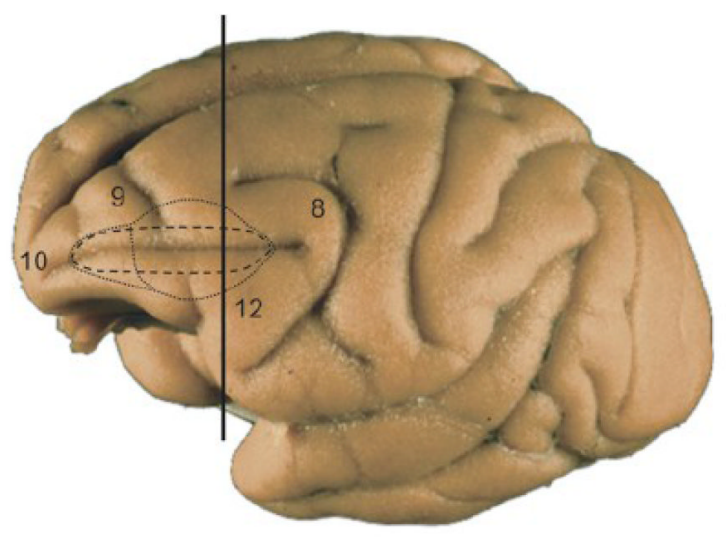

B
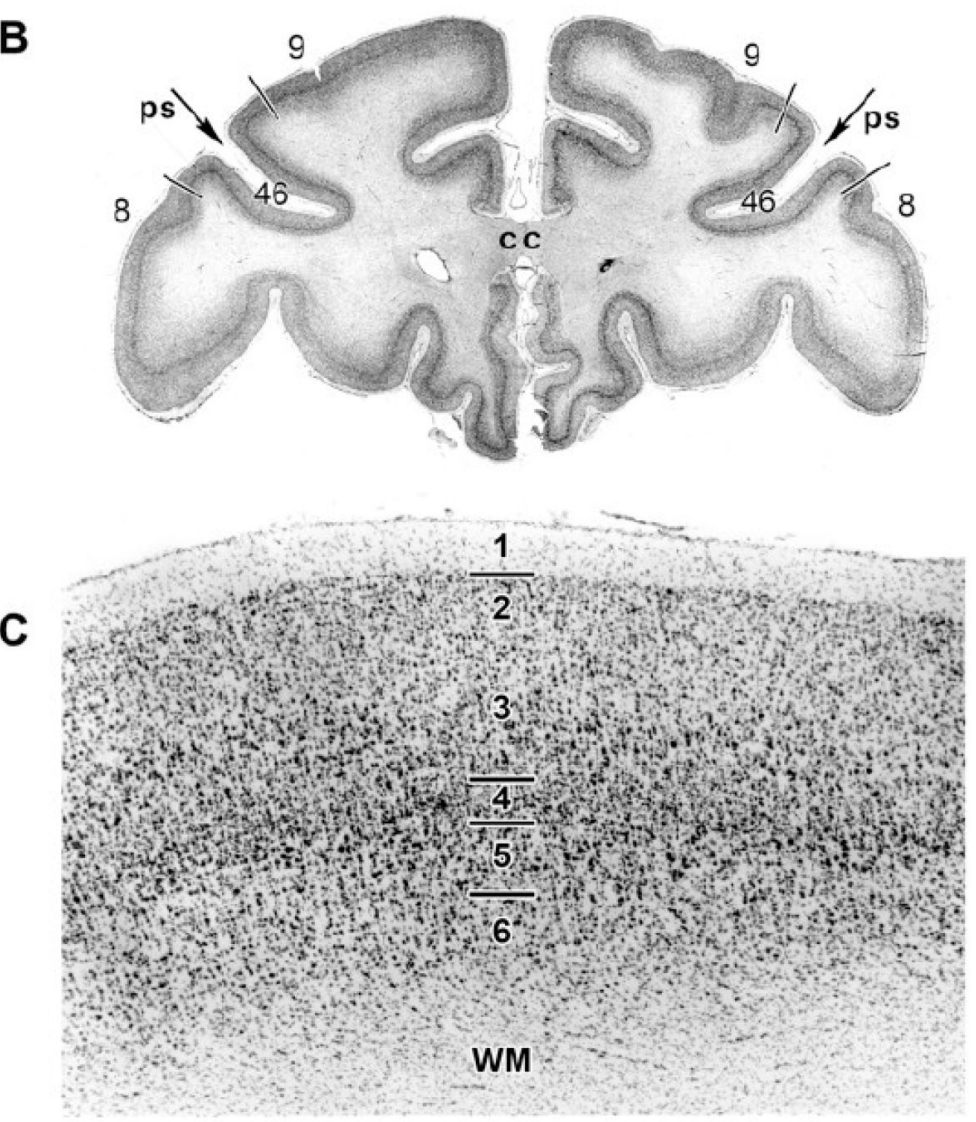

Figure 1.

$A$, Lateral view of the rhesus monkey brain shows the extent of area 46 (small dotted line). Large dashed line is a diagrammatic representation of the upper and lower banks of the principal sulcus. Area 46 is divided into a rostral and a caudal sector (vertical dotted line). The thick vertical line shows the level at which the section shown in $B$ was taken. $\boldsymbol{B}$. Nissl stained coronal section through the frontal lobe at the level of the rostral end of the corpus callosum (cc). The principal sulcus (ps), which is on the lateral surface of the cortex, contains area 46 that extends over the upper and lower lips of the sulcus. $\boldsymbol{C}$. Nissl stained section of area 46 in the lower bank of the principal sulcus shows the appearance of the six cellular layers and the underlying white matter (WM). 


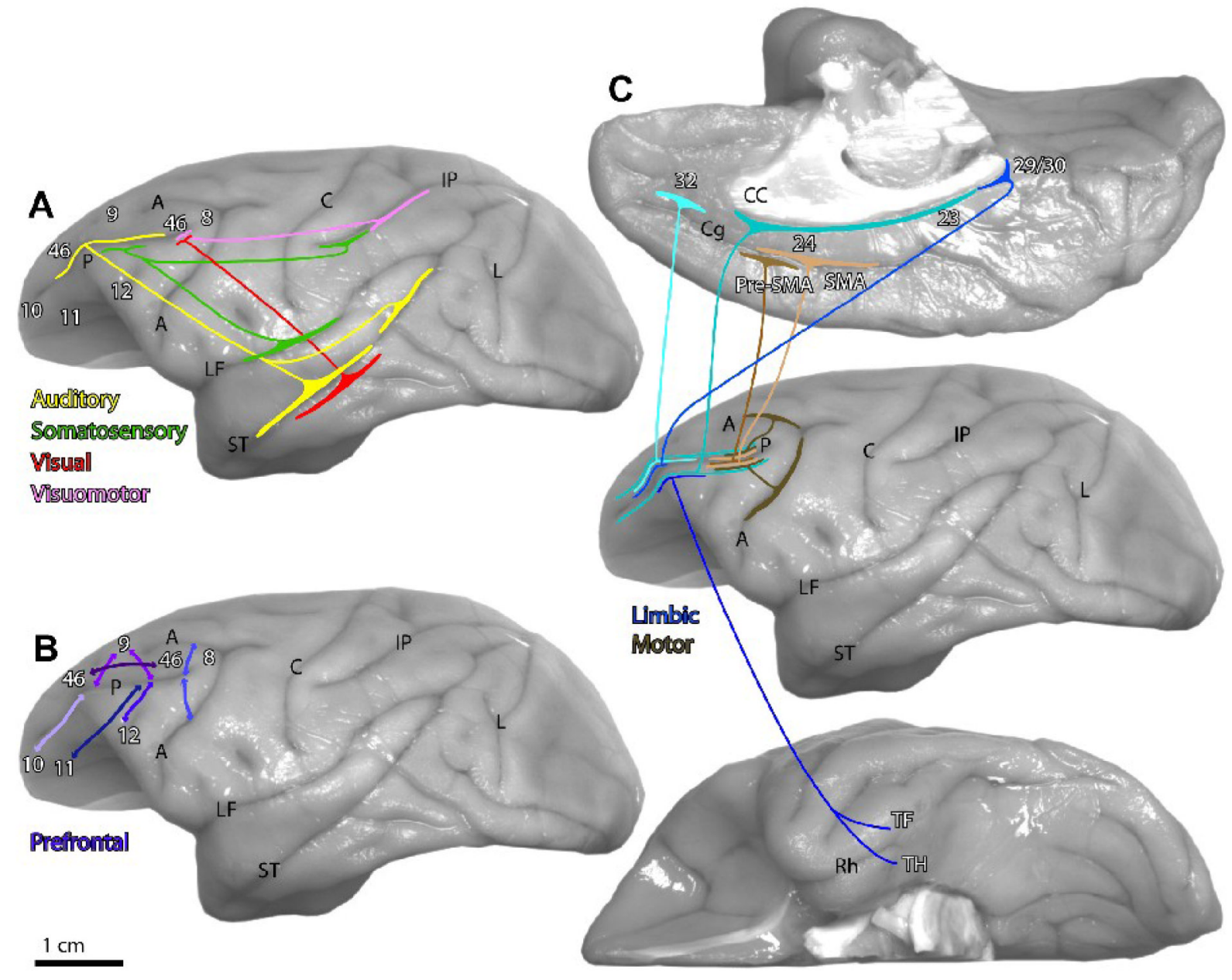

Figure 2.

The principal cortical connections of area 46. A, Lateral view of the rhesus monkey brain shows projections from sensory association areas originating from: visual (red); auditory (yellow); and somatosensory (green) association cortices; Projections are also shown for a visuomotor region in the lateral bank of the intraparietal sulcus (pink). The diagram shows the origin of projections and their termination in area 46, but connections with these cortices are reciprocal. $\boldsymbol{B}$, Interconnections of area 46 within the prefrontal cortex. $\boldsymbol{C}$, Medial (top), lateral (center) and ventral (bottom) views of the rhesus monkey brain show projections from limbic (shades of blue) and premotor cortices (brown). Abbreviations: CC, corpus callosum; names of sulci (shown with black letters): A, arcuate; C, central; Cg, cingulate; IP, intraparietal; L, lunate; LF, lateral fissure; $\mathrm{P}$, principal; Rh, rhinal; ST, superior temporal. Silhouette numbers and letters show architectonic areas: Pre-SMA, pre-supplementary motor area; SMA, supplementary motor area. TF, area TF in anterior medial temporal lobe; $\mathrm{TH}$, area $\mathrm{TH}$ in posterior medial temporal lobe (parahippocampal cortex). 

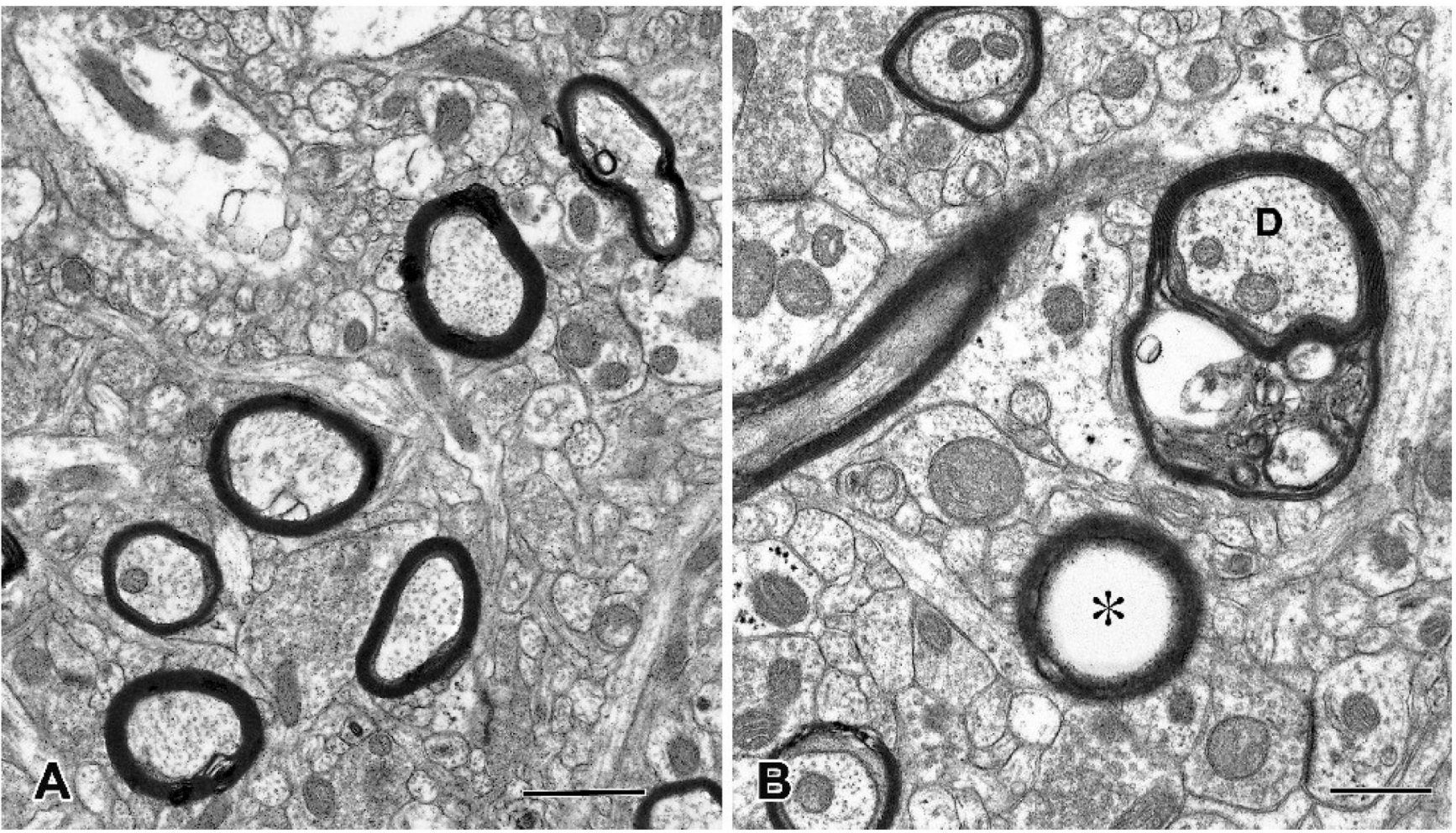

Figure 3.

Electron micrographs show myelinated nerve fibers in area $46 . \boldsymbol{A}$ is from area 46 of a 10 year old monkey and shows that at this age the myelin sheaths around axons are compact. $\boldsymbol{B}$ is from area 46 of a 27 year old monkey, in which many of the myelin sheaths (D) have begun to degenerate and show dense inclusions within their lamellae. Other sheaths (asterisk) are empty because the axon has degenerated. Scale bars equal one micron. 

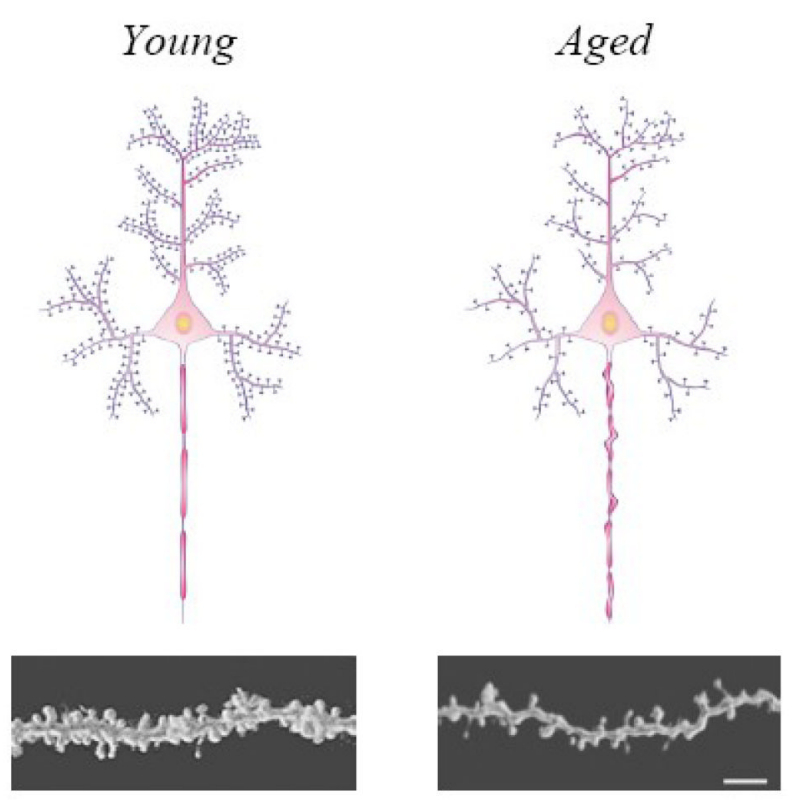

Reduced spine density $\&$ number of asymmetric synapses.
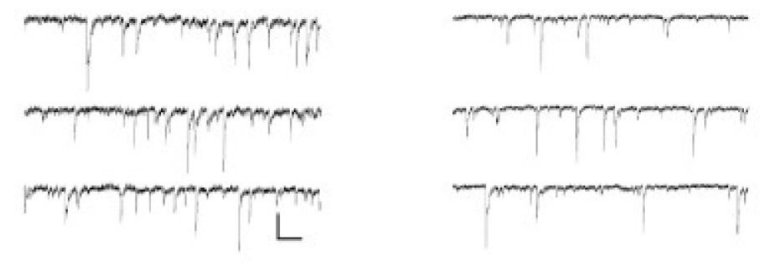

Reduced frequency of glutamatergic synaptic currents.
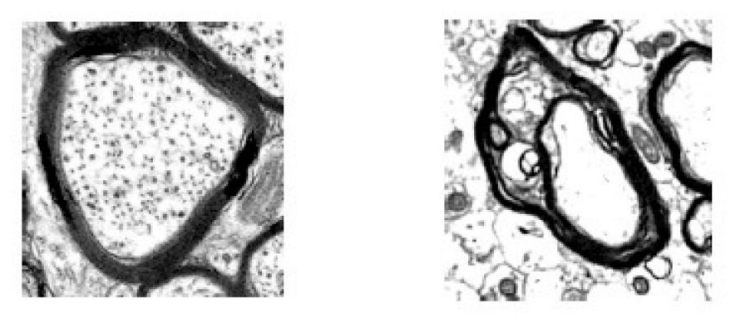

Dystrophic myelin sheaths \& loss of nerve fibers.
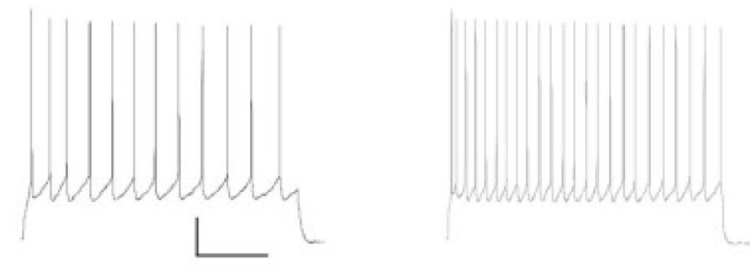

Increased action potential firing frequency.

Figure 4.

Summary of key age-related changes in area 46. Shown at top is a cartoon demonstrating the significant loss of dendritic spines and myelin dystrophy that occurs in pyramidal cells in area 46 with normal aging. Below this cartoon are representative data showing loss of dendritic spines, reduced frequency of glutamatergic synaptic currents, myelin dystrophy and increased action potential firing rates. 


\section{Table 1}

Summary of variables that are known to change with age in Area 46 of the rhesus monkey. DNMs: delayed nonmaking-to-sample task: DRST: delayed recognition span task: CII: Cognitive Impairment Index.

\begin{tabular}{|c|c|c|c|c|}
\hline & $\begin{array}{l}\text { Direction } \\
\text { of Change }\end{array}$ & Task & Correlation $P$ & Citation \\
\hline \multicolumn{5}{|l|}{$\begin{array}{l}\text { Variables that are known to } \\
\text { be } \\
\text { unchanged with age in } \mathrm{A} 46\end{array}$} \\
\hline Number of Neurons & na & na & na & Smith et al. 2004 \\
\hline $\begin{array}{l}\text { Volume(assessed with } \\
\text { neuroanatomical methods) }\end{array}$ & na & na & na & O'Donnell et al. 1999 \\
\hline $\begin{array}{l}\text { Layer } 5 \text { pyramidal Cell-action } \\
\text { potential frequency }\end{array}$ & na & na & na & Luebke \& Chang, 2007 \\
\hline $\begin{array}{l}\text { Layer } 5 \text { pyramidal Cell-slow } \\
\text { AHP amplitude }\end{array}$ & na & na & na & Luebke et al.,(submitted) \\
\hline \multicolumn{5}{|l|}{$\begin{array}{l}\text { Variables that change with } \\
\text { age in } \mathrm{A46} \\
\text { not tested for correlation } \\
\text { with behavior }\end{array}$} \\
\hline $\begin{array}{l}\text { Layer } 3 \text { pyramidal Cell- } \\
\text { density of dendritic spines }\end{array}$ & Decreased & na & na & Duan et al, 2003 \\
\hline $\begin{array}{l}\text { Layer } 3 \text { pyramidal Cell- } \\
\text { frequency of glutamatergic } \\
\text { EPSCs }\end{array}$ & Decreased & na & na & Luebke et al. 2004 \\
\hline $\begin{array}{l}\text { Layer } 3 \text { pyramidal Cell- } \\
\text { frequency of GABAergic } \\
\text { IPSCs }\end{array}$ & Increased & na & na & Luebke et al. 2004 \\
\hline Dopamine levels & Decreased & na & na & $\begin{array}{l}\text { Goldman-Rakic and } \\
\text { Brown, } 1981 \text { Wenk et al., } \\
1989\end{array}$ \\
\hline NE receptors & Decreased & na & na & Moore et al.,2005 \\
\hline 5-HT receptors & Decreased & na & na & $\begin{array}{l}\text { Goldman-Rakic, and } \\
\text { Brown, 1981 Wenk et al., } \\
\text { 1989; Bigham, and } \\
\text { Lidow, } 1995\end{array}$ \\
\hline Chat, $\mathrm{MI}$ receptors & ?/Decreased & na & na & $\begin{array}{l}\text { Vannucchi, and } \\
\text { Goldman-Rakic, } 1991\end{array}$ \\
\hline \multicolumn{5}{|l|}{$\begin{array}{l}\text { Variables that change with } \\
\text { age in A46 } \\
\text { and do NOT correlate with } \\
\text { behavior }\end{array}$} \\
\hline Number of senile plaques & Increased & CII & na & Sloane et al.,1997 \\
\hline Number of oligodendrocytes & Increased & CII & na & Peters et al. (unpublished) \\
\hline $\begin{array}{l}\text { Number of synapses in Layer } \\
5 / 6\end{array}$ & Decreased & CII & na & Peters et al.,2008 \\
\hline \multicolumn{5}{|l|}{$\begin{array}{l}\text { Variables that change with } \\
\text { age in } \mathbf{A 4 6} \\
\text { and correlate with behavior }\end{array}$} \\
\hline $\begin{array}{l}\text { Gray matter volumes } \\
\text { (assessed with MBI) }\end{array}$ & Decreased & $\begin{array}{l}\text { DRST } \\
\text { best DNMS }\end{array}$ & $\begin{array}{l}\mathrm{p}<0.008 \\
\text { na }\end{array}$ & Alexander et al.,2008 \\
\hline "Strength" of microcolumns & Decreased & CII & $\mathrm{p}<0.01$ & Cruz et al.,2004 \\
\hline Thickness of Layer 1 & Decreased & $\operatorname{DNMS}\left(2^{\prime}\right)$ & $\mathrm{p}<0.03$ & Peters et al., 1998 \\
\hline $\begin{array}{l}\text { Number of synapses (total) in } \\
\text { Layer } 1\end{array}$ & Decreased & CII & $\mathrm{p}<0.05$ & Peters et al.,1998 \\
\hline
\end{tabular}




\begin{tabular}{lllll}
\hline & $\begin{array}{l}\text { Direction } \\
\text { of Change }\end{array}$ & Task & Correlation $\boldsymbol{P}$ & Citation \\
$\begin{array}{l}\text { Number of asymmetric } \\
\text { synapses in Layer 2/3 }\end{array}$ & Decreased & CII & $\mathrm{p}<0.008$ & Peters et al.,2008 \\
$\begin{array}{l}\text { Number of symmetric } \\
\text { synapses in Layer 2/3 }\end{array}$ & Decreased & CII & $\mathrm{p}<0.08$ & Peters et al.,2008 \\
$\begin{array}{l}\text { Number of abnormal myelin } \\
\text { sheaths }\end{array}$ & Increased & CII & $\mathrm{p}<0.001$ & Peters et al.,2002 \\
$\begin{array}{l}\text { Number of paranodes } \\
\begin{array}{l}\text { Layer 2/3 pyramidal cell-slow } \\
\text { AHP amplitude }\end{array}\end{array}$ & Increased & CII & $\mathrm{p}<0.01$ & Peters and Sethares,2003 \\
$\begin{array}{l}\text { Layer 2/3 pyramidal cell- } \\
\text { action potential frequency }\end{array}$ & Increased & CII,DNMS,DRST & $\mathrm{p}<0.03$ & Luebke et al.,(submitted) \\
\hline
\end{tabular}

